\title{
Central-Pacific surface meteorology from the 2016 El Niño Rapid Response (ENRR) field campaign
}

\author{
Leslie M. Hartten ${ }^{1,2}$, Christopher J. Cox ${ }^{1,2}$, Paul E. Johnston ${ }^{1,2}$, Daniel E. Wolfe ${ }^{1,2}$, Scott Abbott ${ }^{2}$, and \\ H. Alex McColl ${ }^{1,2, a}$ \\ ${ }^{1}$ Cooperative Institute for Research in Environmental Science (CIRES), University of Colorado, \\ Boulder, CO 80309-0216, USA \\ ${ }^{2}$ NOAA/Earth System Research Laboratory, Physical Sciences Division, Boulder, Colorado, CO 80305, USA \\ ${ }^{a}$ currently at: Berthoud, CO 80513, USA \\ Correspondence: Leslie M. Hartten (leslie.m.hartten@noaa.gov)
}

Received: 7 November 2017 - Discussion started: 6 December 2017

Revised: 23 April 2018 - Accepted: 30 May 2018 - Published: 20 June 2018

\begin{abstract}
During the early months of the 2015/2016 El Niño event, scientists led by the Earth System Research Laboratory's Physical Sciences Division conducted the National Oceanic and Atmospheric Administration's (NOAA's) El Niño Rapid Response (ENRR) field campaign. One component of ENRR involved in situ observations collected over the near-equatorial eastern-central Pacific Ocean. From 25 January to 28 March 2016, standard surface meteorology observations, including rainfall, were collected at Kiritimati Island $\left(2.0^{\circ} \mathrm{N}, 157.4^{\circ} \mathrm{E}\right)$ in support of twice-daily radiosonde launches. From 16 February to 16 March 2016, continuous measurements of surface meteorology, sea surface temperature, and downwelling shortwave radiation were made by NOAA Ship Ronald H. Brown. These were largely done in support of the four to eight radiosondes launched each day as the ship travelled from Hawaii to TAO buoy locations along longitudes 140 and $125^{\circ} \mathrm{W}$ and then back to port in San Diego, California. The rapid nature of these remote field deployments led to some specific challenges in addition to those common to many surface data collection efforts. This paper documents the two deployments as well as the steps taken to evaluate and process the data. The results are two multi-week surface meteorology data products and one accompanying set of surface fluxes, all collected in the core of the eastern-central Pacific's extremely warm waters. These data sets, plus metadata, are archived at the NOAA's National Centers for Environmental Information (NCEI) and are free for public access: surface meteorology from Kiritimati Island (https://doi.org/10.7289/V51Z42H4); surface meteorology and some surface fluxes from NOAA Ship Ronald H. Brown (https://doi.org/10.7289/V5SF2T80; https://doi.org/10.7289/V58050VP).
\end{abstract}

\section{Introduction}

In June 2015, the weak El Niño conditions that had existed since March 2015 were strengthening and forecasters were confident that they would continue to do so through winter 2015/2016 (Climate Prediction Center (CPC) and International Research Institute for Climate and Society (IRI), 2015). The United States' National Oceanic and Atmospheric Administration (NOAA) wanted to quickly address the unfolding event, which had the potential for large domestic impacts, particularly on the country's Pacific coast, and thus developed the El Niño Rapid Response (ENRR).
The Earth System Research Laboratory's (ESRL) Physical Sciences Division (PSD) led the design and implementation of one component, the ENRR field campaign (Dole et al., 2018). Among the many assets put into play were surface meteorological instruments on Kiritimati (pronounced "Christmas") Island and aboard NOAA Ship Ronald H. Brown. The primary purpose of the surface meteorological measurements was to provide initialization data for the radiosondes launched twice a day from Kiritimati and four to eight times per day from NOAA Ship Ronald H. Brown (Hartten et al., 2018). However, the high temporal resolution of the surface 
(a)

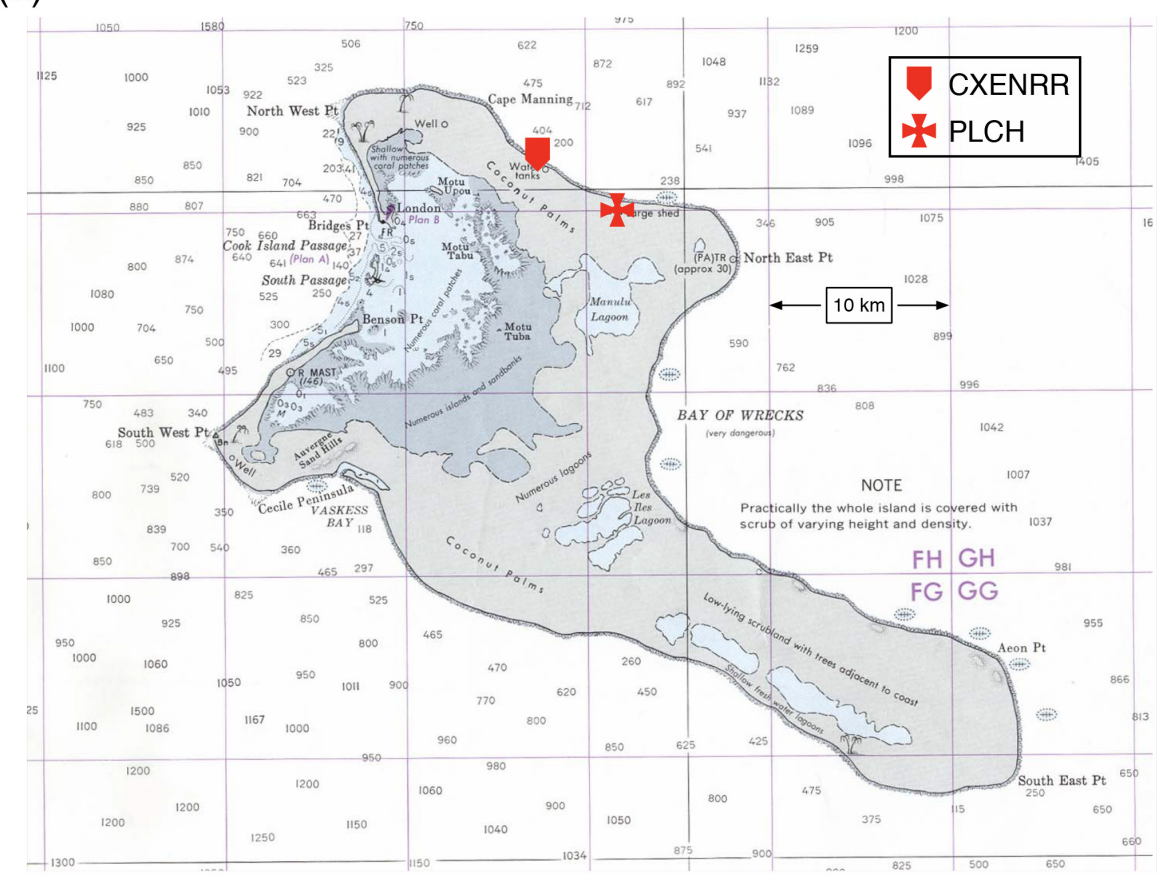

(b)

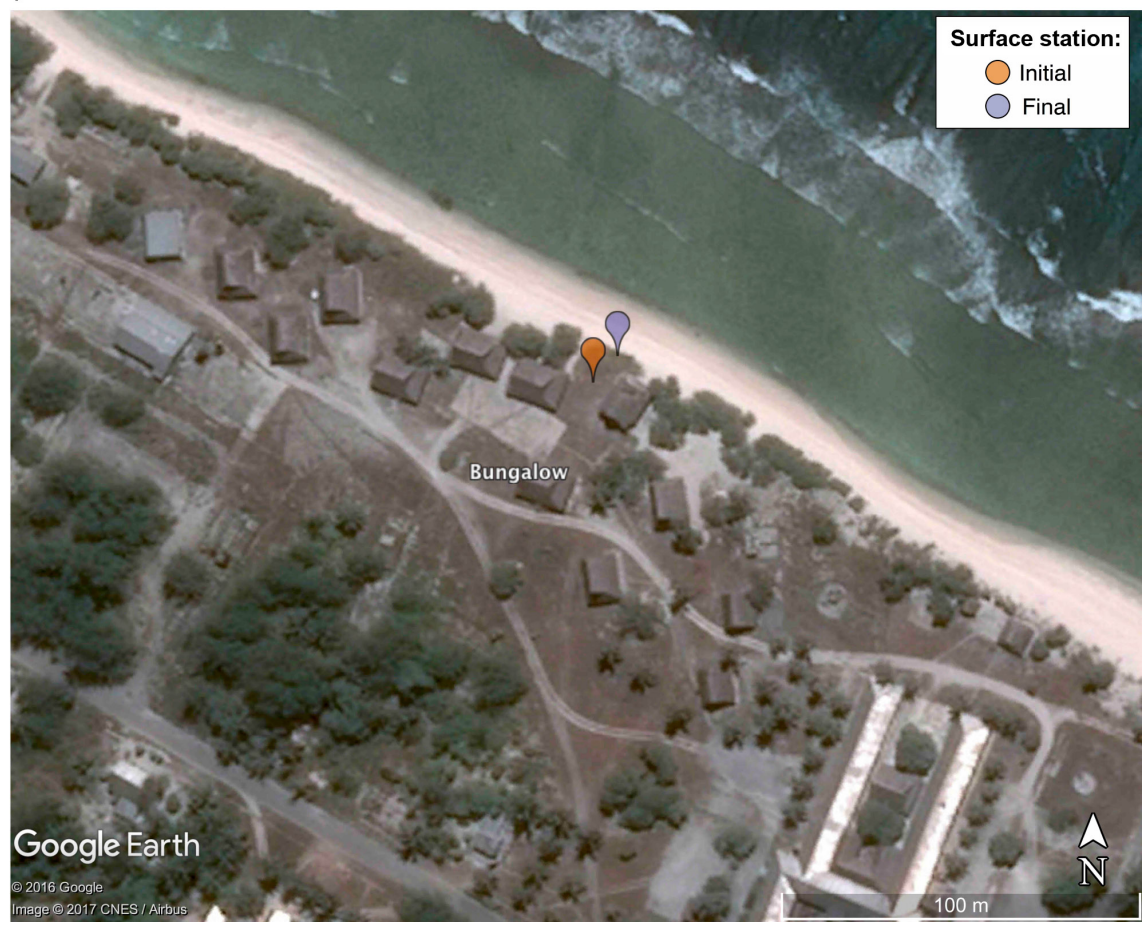

Figure 1. (a) Map of Kiritimati showing the locations of Cassidy International Airport (PLCH) and CXENRR. Kiritimati map excerpted from U.S. Defense Mapping Agency (DMA) Stock No. 83BHA83130, courtesy of the University of Texas Libraries, The University of Texas at Austin. Map data from surveys by New Zealand (1938-1941) and the U.S. Navy (to 1962). Heights are in feet above mean high water springs; soundings are in fathoms (or fathoms and feet if less than 11 fathoms). (b) Detail of the CXENRR site at the Captain Cook Hotel. The bungalow which served as our base of operations is in the center of the image, with markers to its north indicating the initial and final locations of the surface meteorological instruments. 
Table 1. Surface meteorology instruments deployed at Kiritimati Island during the ENRR field campaign.

\begin{tabular}{|c|c|c|c|c|c|}
\hline Instrument & Height (a.s.1.) & Parameter & $\begin{array}{l}\text { Collection rate; } \\
\text { logged values }\end{array}$ & Accuracy & Operational notes \\
\hline $\begin{array}{l}\text { Vaisala PTB101B } \\
\text { attached to a SPH10 } \\
\text { static pressure head }\end{array}$ & $3.6 \mathrm{~m}$ & $\begin{array}{l}\text { Atmospheric } \\
\text { pressure }\end{array}$ & $1 \mathrm{~Hz}$; averaged* & $\begin{array}{l} \pm 0.5 \mathrm{hPa} \text { at } 20^{\circ} \mathrm{C} \\
\pm 1.5 \mathrm{hPa} \text { at } \\
0-40{ }^{\circ} \mathrm{C}\end{array}$ & \\
\hline \multirow[t]{2}{*}{$\begin{array}{l}\text { Vaisala HMP45C in an } \\
\text { R.M. Young } 41003-5 \\
\text { 10-plate naturally as- } \\
\text { pirated solar radiation } \\
\text { shield }\end{array}$} & \multirow[t]{2}{*}{$4.4 \mathrm{~m}$} & Air temperature & $1 \mathrm{~Hz}$; averaged* & $\begin{array}{l} \pm 0.2{ }^{\circ} \mathrm{C} \text { at } 20^{\circ} \mathrm{C} \\
\pm 0.25^{\circ} \mathrm{C} \text { at } 30^{\circ} \mathrm{C}\end{array}$ & \multirow[t]{2}{*}{$\begin{array}{l}\text { Sensor bad starting } 1 \text { Febru- } \\
\text { ary 2016, 17:59:43 UTC and } \\
\text { was replaced } 7 \text { February 2016, } \\
03: 41: 43 \text { UTC }\end{array}$} \\
\hline & & $\begin{array}{l}\text { Relative } \\
\text { humidity }\end{array}$ & $1 \mathrm{~Hz}$; averaged* & $\begin{array}{l}\text { at } 20^{\circ} \mathrm{C}: \\
\pm 2 \%(0-90 \% \mathrm{RH}) \\
\pm 3 \%(90-100 \% \mathrm{RH})\end{array}$ & \\
\hline \multirow[t]{3}{*}{$\begin{array}{l}\text { R.M. Young } 5103 \\
\text { anemometer }\end{array}$} & \multirow[t]{3}{*}{$6.6 \mathrm{~m}$} & Wind speed & \multirow[t]{2}{*}{$\begin{array}{l}1 \mathrm{~Hz} ; \\
\text { vector-averaged* }\end{array}$} & $\begin{array}{l} \pm 0.3 \mathrm{~m} \mathrm{~s}^{-1} \text { or } \\
1 \% \text { of reading }\end{array}$ & \\
\hline & & Wind direction & & $\pm 3^{\circ}$ & \\
\hline & & $\begin{array}{l}\text { Maximum } \\
\text { wind speed }\end{array}$ & $\begin{array}{l}1 \mathrm{~Hz} \text {; maximum } \\
\text { during collection* }\end{array}$ & & \\
\hline $\begin{array}{l}\text { Texas Electronics } \\
\text { TE525 tipping bucket }\end{array}$ & $4.4 \mathrm{~m}$ & Rain & $\begin{array}{l}\text { Accumulation } \\
\text { during collection* }\end{array}$ & $\begin{array}{l} \pm 1 \% \text { up to } \\
25.4 \mathrm{~mm} \mathrm{~h}^{-1} \\
+0,3 \% \text { from } \\
25.4 \text { to } 50.8 \mathrm{~mm} \mathrm{~h}^{-1} \\
+0,-5 \% \text { from } \\
50.8 \text { to } 76.2 \mathrm{~mm} \mathrm{~h}^{-1}\end{array}$ & $0.254 \mathrm{~mm}$ per tip \\
\hline $\begin{array}{l}\text { Campbell Scientific } \\
\text { CR23X datalogger }\end{array}$ & $3.6 \mathrm{~m}$ & Battery voltage & $1 \mathrm{~Hz}$; averaged* & $\mathrm{n} / \mathrm{a}$ & $\begin{array}{l}\text { Power supply failed; } \\
\text { no data logged from } \\
15 \text { March 2016, 11:12:43 UTC } \\
\text { to 16 March 2016, } \\
\text { 05:04:42 UTC }\end{array}$ \\
\hline
\end{tabular}

* The averaging or collection period was 2 min through 11 February 2016, 04:05:43. It changed to 1 min starting 11 February 2016.

measurements in these remote locations makes them useful in their own right. The quick deployment and remote locations led to several data challenges which needed to be overcome both for the sake of creating research-quality radiosonde data sets and to enable the independent value of the surface data to be more fully realized. This article documents the data collection, the problems identified, and corrections applied after the field phase, and the resulting data sets.

\section{Instrument specifications and siting}

\subsection{Kiritimati Island, Republic of Kiribati}

Kiritimati is one of the Line Islands, a chain of islands and atolls lying across the Equator south of Hawaii. Its land area of $321 \mathrm{~km}^{2}$ makes it the world's largest coral atoll (Scott, 1993); its lagoons cover a similar area (Fig. 1a). Much of it lies a few meters above sea level, with its highest point only 13 ma.s.l. Kiritimati's 6456 inhabitants as well as all visitors live in four towns on the northern side of the is- land (Morate, 2016). The Kiribati ${ }^{1}$ Meteorological Service maintains and staffs an office at Cassidy International Airport along the northeast-facing coastline; observers record surface conditions hourly and report them under WMO station ID 91490. Its position in the equatorial central Pacific, coupled with its relatively large land area and advanced infrastructure, have made Kiritimati Island the site of choice for many previous scientific efforts, including the Line Islands Experiment (Zipser, 1970); the multi-year deployment of wind-profiling radars (Gage et al., 1991); climatological studies using coral (Evans et al., 1999); and the Pacific Atmospheric Sulfur Experiment (PASE; Conley et al., 2009).

ENRR operations were based at the Captain Cook Hotel, which is located on the northeast-facing coast about $6 \mathrm{~km}$ from the airport (Fig. 1a). This location was chosen because it was familiar to some of our staff; had experience hosting scientific fieldwork; had $60 \mathrm{~Hz}, 120 \mathrm{~V}$ power and Internet access; and had enough driveable paths, staff presence, and public lighting to provide a level of safety during evening radiosonde launches. Field staff lived in a two-unit bungalow

\footnotetext{
${ }^{1}$ The country's name is pronounced "KEER-eh-bahss".
} 
(a)

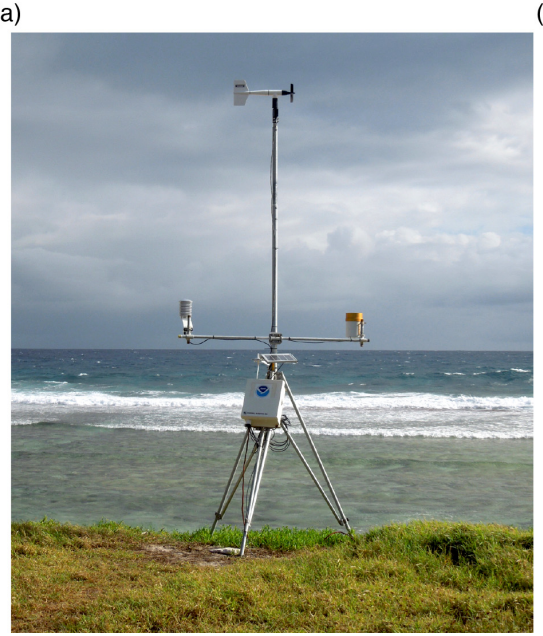

(b)

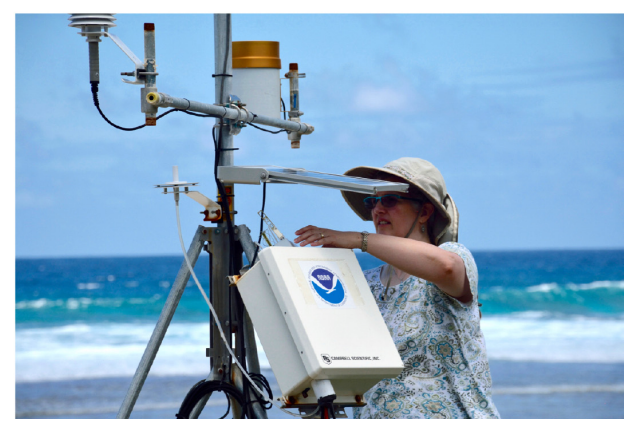

Figure 2. (a) The surface met station in its final position above the beach at Kiritimati. The anemometer sits atop the assembly, while the temperature-humidity sensor (on the left) and rain gauge (on the right) are attached to the crossbeam. Just below the crossbeam is the solar panel, and the box containing the Campbell datalogger, the power supply, and the barometer is mounted just below that. A plastic tube runs from the barometer out the tube on the bottom of the box, and can be seen mounted within a white disk just to the left of the solar panel. (b) The 26 March 2017, 00:00 UTC radiosonde being put on the Campbell box in the shade of the solar panel prior to launch. The pressure tube egress and mount are clearly visible. Photo courtesy of Gabriele Kerber.

(a)

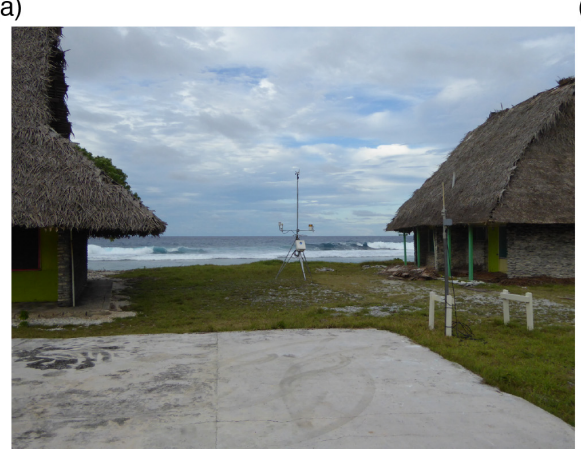

(b)

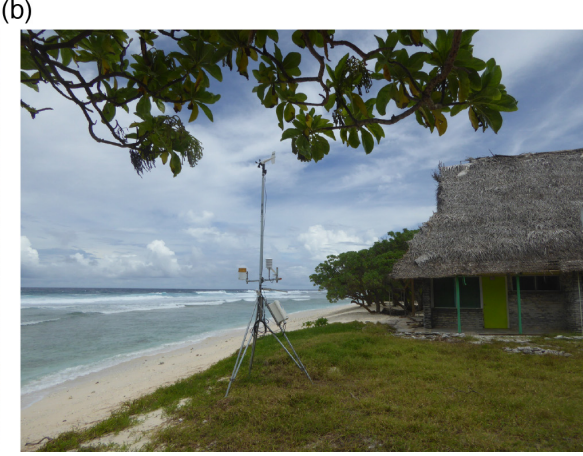

Figure 3. The original position of the surface instruments (a), and their location after being moved back towards the top of the beach on 5 February 2017 (b).

(Fig. 1b). One unit doubled as office space, housing the computers and radiosonde equipment, and for a few weeks supplied power to the outdoor instruments. The bungalow was usually air-conditioned with the temperature set to $24-26^{\circ} \mathrm{C}$. The site was located at $\left(2.01^{\circ} \mathrm{N}, 157.40^{\circ} \mathrm{W}\right)$, and upper-air observations were transmitted to the Global Telecommunication System (GTS) using "CXENRR" as a station name.

On 25 January 2016 (UTC), the first day of operations, the surface meteorological instruments were attached to a tripod (Fig. 2) located about $14 \mathrm{~m}$ northeast of the concrete pad seen in Fig. 1b. Table 1 contains information about the surface meteorology instruments deployed, the variables measured, and recording details. A solar panel was also attached to the tripod; it was used to charge the battery that ran the Campbell datalogger. This initial location was further from our bungalow than expected, and we had no cable long enough to con- nect directly to the computers inside the bungalow, so surface conditions could not be monitored in real time and an observer had to go out and read instantaneous surface values directly off the Campbell datalogger during the radiosonde ground check and initialization. Within a few days staff realized that the initial location was somewhat obstructed by the two nearby bungalows (Figs. 1b and 3a), which were approximately $12 \mathrm{~m}$ apart from each other. On 5 February the tripod was moved northeast about $10 \mathrm{~m}$, to a location near the top of the beach (Figs. 1b and 3b) that was further from the bungalows, and a newly arrived $30 \mathrm{~m}$ cable was run between the station and the computers in our bungalow. This second location was also somewhat obstructed (Fig. 3b), with a tree about $12 \mathrm{~m}$ to the west-northwest and the two bungalows about $15 \mathrm{~m}$ to the southwest and $6 \mathrm{~m}$ to the south. However, it was believed superior because of its more open setting 
(a)

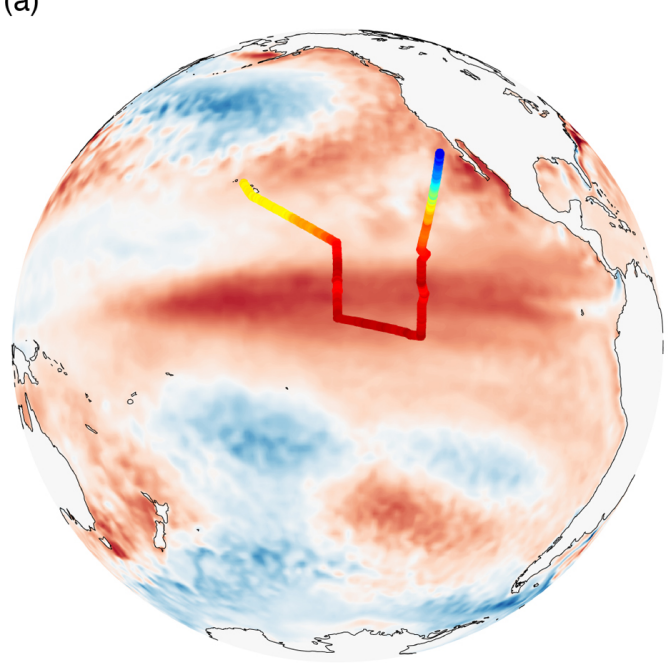

(b)

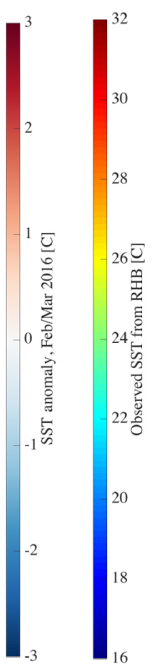

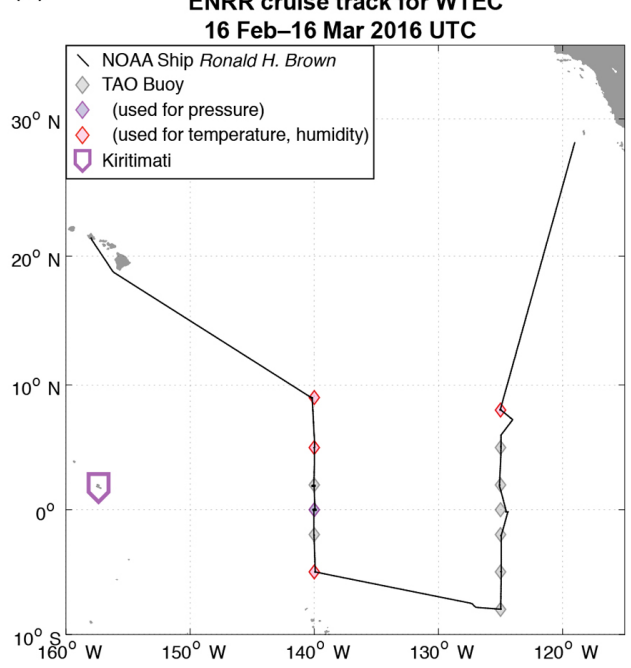

Figure 4. (a) SSTs observed by NOAA Ship Ronald H. Brown during ENRR, overlaid on SST anomalies. The latter are the departure from the ERA-Interim (Dee et al., 2011) 1979-2016 February through March mean. (b) The cruise track of NOAA Ship Ronald H. Brown overlaid on a map showing the location of the TAO buoys visited during its cruise and also the location of Kiritimati Island. The buoys used in the post-processing of the ship's surface pressure, temperature, and humidity are highlighted.

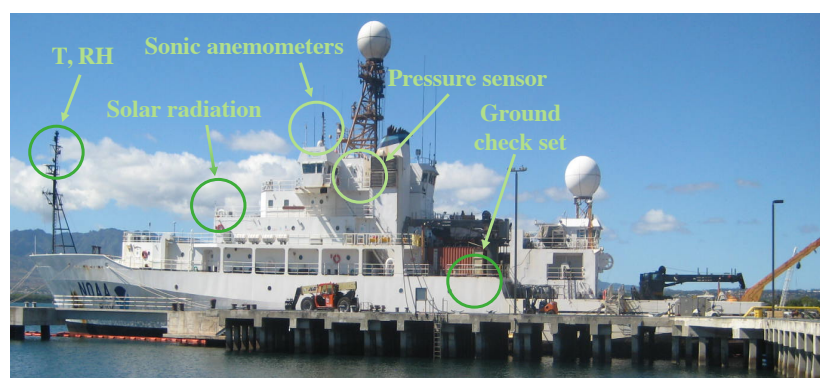

Figure 5. The location of key surface meteorological instruments on NOAA Ship Ronald H. Brown.

and long fetch over a $180^{\circ}$ sector. This setup was maintained through 28 March 2016, the last day of CXENRR operations.

\subsection{NOAA Ship Ronald H. Brown}

NOAA Ship Ronald H. Brown is a Global Class ${ }^{2}$ research vessel in service since 1997 as part of the NOAA Marine Operations Center - Atlantic (MOC-A) fleet. The vessel is $83.5 \mathrm{~m}$ long with a $16.2 \mathrm{~m}$ beam and has a cruising speed of 11 knots. When the ENRR field campaign was being planned, the ship was already scheduled to cruise from Hawaii to San Diego during February and March 2016 to conduct routine maintenance of buoys that are part of the Tropical Atmosphere Ocean (TAO) array along $9^{\circ} \mathrm{N}$ to $8^{\circ} \mathrm{S}$

\footnotetext{
2"Global Class ships are the largest and most capable with the ability to work worldwide with large scientific parties and the longest endurance" (Joint Subcommittee on Ocean Science and Technology (JSOST), 2016).
}

meridional transects at 140 and $125^{\circ} \mathrm{W}$ (Fig. 4). Because the scheduled timing and path of the ship were well suited for the objectives of the ENRR campaign, three scientists from ENRR were deployed with the ship to acquire soundings for the full duration of the cruise. These were transmitted to the GTS as TEMP MOBILE messages using the station name "WTEC".

The ENRR surface meteorology and oceanographic observations were collected by some of the ship's standard instrumentation suite (Fig. 5). Technical information about the instruments deployed, the variables measured, measurement and recording details, and operation notes are given in Table 2. As at Kiritimati, our primary interest in the surface meteorological data collected during the cruise was for the radiosonde ground check and initialization. The radiosondes were launched four to eight times per day from the main deck of the ship, and the Vaisala GC25 ground-check set was located indoors on the main deck of the ship approximately $3.8 \mathrm{~m}$ above the ship's designated water line.

\section{Observational issues and post-deployment data correction}

There were difficulties with some surface measurements at both Kiritimati Island and aboard NOAA Ship Ronald $H$. Brown. Some problems were almost immediately apparent; others became known as the campaign unfolded or upon post-deployment review. The problems and the methods used to correct them were different for each site and are described below. Only those measured quantities that required detailed 
Table 2. Surface meteorology instruments deployed aboard NOAA Ship Ronald H. Brown during the ENRR field campaign. The Improved Meteorology (IMET, Hosom et al., 1995) instruments are modified versions of the original manufacturer instruments, as described in the Woods Hole Oceanographic Institution (WHOI, 2010a, 2010b).

\begin{tabular}{|c|c|c|c|c|c|}
\hline Instrument & Height (a.s.1.) & Parameter & $\begin{array}{l}\text { Collection rate; } \\
\text { logged values }\end{array}$ & Accuracy & Operational notes \\
\hline Vaisala PTB330 & $15.24 \mathrm{~m}$ & $\begin{array}{l}\text { Atmospheric } \\
\text { pressure }\end{array}$ & $\begin{array}{l}1 \mathrm{~Hz} ; \\
\text { averaged* }^{*}\end{array}$ & $\begin{array}{l} \pm 0.20 \mathrm{hPa} \text { at } 20^{\circ} \mathrm{C} \\
\pm 0.25(\mathrm{~B}) \text { at } \\
0 \text { to } 40^{\circ} \mathrm{C}\end{array}$ & $\begin{array}{l}\text { Mounted on bridge } \\
\text { Calibrated } 29 \text { December } \\
2015\end{array}$ \\
\hline \multirow[t]{2}{*}{$\begin{array}{l}\text { IMET } \\
\text { Rotronic MP101A }\end{array}$} & \multirow[t]{2}{*}{ approx. $15 \mathrm{~m}$} & Air temperature & \multirow[t]{2}{*}{$\begin{array}{l}1 \mathrm{~Hz} ; \\
\text { averaged* }^{*}\end{array}$} & $\pm 0.05^{\circ} \mathrm{C}$ & \multirow[t]{2}{*}{$\begin{array}{l}\text { Mounted on bow mast } \\
\text { Calibrated } 26 \text { July } 2014\end{array}$} \\
\hline & & Relative humidity & & $\pm 1 \%$ & \\
\hline \multirow[t]{2}{*}{$\begin{array}{l}\text { Vaisala WMT700 } \\
\text { ultrasonic } \\
\text { anemometers }\end{array}$} & \multirow[t]{2}{*}{ approx. $19 \mathrm{~m}$} & Wind speed & \multirow[t]{2}{*}{$\begin{array}{l}1 \mathrm{~Hz} \\
\text { vector- } \\
\text { averaged }^{*}\end{array}$} & $\begin{array}{l} \pm 0.1 \mathrm{~m} \mathrm{~s}^{-1} \text { or } \\
2 \% \text { of reading }\end{array}$ & \multirow[t]{2}{*}{$\begin{array}{l}\text { Mounted on poles atop the } \\
\text { port and starboard sides of } \\
\text { the bridge roof }\end{array}$} \\
\hline & & Wind direction & & $\pm 2^{\circ}$ & \\
\hline $\begin{array}{l}\text { Sea Bird SBE45 } \\
\text { thermosalinograph }\end{array}$ & $-5 \mathrm{~m}$ & $\begin{array}{l}\text { Sea surface } \\
\text { temperature }\end{array}$ & $\begin{array}{l}1 \mathrm{~Hz} ; \\
\text { averaged }^{*}\end{array}$ & $\pm 0.002{ }^{\circ} \mathrm{C}$ & \\
\hline IMET Eppley PSP & $11.2 \mathrm{~m}$ & $\begin{array}{l}\text { Downwelling } \\
\text { shortwave radiation }\end{array}$ & $\begin{array}{l}1 \mathrm{~Hz} ; \\
\text { averaged }^{*}\end{array}$ & $\pm 2 \%$ & \\
\hline \multirow[t]{3}{*}{ Furuno GP90 } & \multirow[t]{3}{*}{ approx. $17 \mathrm{~m}$} & Latitude, longitude & \multirow[t]{3}{*}{$\begin{array}{l}1 \mathrm{~Hz} ; \\
\text { averaged* }^{*}\end{array}$} & $\pm 10 \mathrm{~m}$ & \\
\hline & & Course over ground & & $\begin{array}{l} \pm 3^{\circ} \text { at } 1-17 \mathrm{kt} \\
\pm 1^{\circ} \text { at }>17 \mathrm{kt}\end{array}$ & \\
\hline & & Speed over ground & & $\begin{array}{l}0.2 \mathrm{kt} \text { at } \leq 10 \mathrm{kt} \\
2 \% \text { of ship speed }\end{array}$ & \\
\hline Sperry MK37 & unknown & Heading & $\begin{array}{l}1 \mathrm{~Hz} ; \\
\text { averaged* }\end{array}$ & unknown & \\
\hline
\end{tabular}

* The averaging or collection period was $1 \mathrm{~min}$.

post-deployment analysis are discussed in subsections; all other information is given in the main site sections.

\subsection{Kiritimati Island}

Issues in the original Kiritimati Island surface data fall into five categories: instrument calibration issues; instrument failures; non-representativeness of the data caused by poor siting; changes in the data acquisition methods and archival timing; and gaps in the data. Some of these issues were consequences of the "Rapid Response" aspect of the project. Because there is only one international flight to Kiritimati Island each week and the campaign was pulled together in only a few months, there was no time for a site survey prior to the start of fieldwork. This limited the choices of available sites and led to some of the shipped equipment being our "best guess" at what would be needed. It also meant that we often had to make do with what was available on the island, or wait a week or more until something could be shipped.
The "Rapid Response" also affected the exact instruments deployed, which had to be those available on short notice from PSD's instrument pool. Questions about the calibration of some of them arose soon after the campaign started, which led us to develop a practice of placing the initialized Vaisala RS92 radiosonde atop the instrument box for an extended period before launch. Radiosonde initialization, which was done inside the air-conditioned bungalow, includes a ground-check procedure that uses high-precision and high-accuracy temperature and humidity sensors to calibrate each radiosonde (Vaisala Oyj, 2006, 2015). Setting the radiosonde in the shade of the surface station's solar panel (Fig. 2b) allowed the radiosonde to equilibrate to the outside environment; it also provided as much as several minutes of co-located pressure, temperature, and humidity data from the radiosonde and the surface instruments. Details of how we used these coincident measurements to refine the surface observations are discussed in the relevant subsections below, and are in accord with Wang et al.'s (2002) suggestion that "comparisons of prelaunch radiosonde data with the surface 
Table 3. Major gaps in the Kiritimati surface data set. Data collection started 25 January 2016, 03:07:43 UTC and ended 28 March 2016, 19:14:42 UTC.

\begin{tabular}{llll}
\hline Start of gap (UTC) & End of gap (UTC) & Reason & Measurement(s) affected \\
\hline 25 January 2016, 03:07:43 & 26 January 2016, 21:49:43 & Sensor not aligned & Wind direction \\
1 February 2016, 17:59:43 & 7 February 2016, 03:41:43 & Sensor failure and replacement & Temperature, relative humidity \\
5 February 2016, 21:21:43 & 5 February 2016, 22:01:43 & Surface station relocation & All \\
15 March 2016, 11:12:43 & 16 March 2016, 05:04:42 & Solar panel failure and power & All \\
& & supply replacement & \\
\hline
\end{tabular}

data from independent surface sensors can always be used to evaluate the accuracy of radiosonde data (and/or surface data), and may provide some guidance on how to correct the data".

There were two instrument failures during the experiment. During the second week of operations it became clear that the temperature-humidity probe had failed. Fortunately, we had brought a second unit with us. We swapped the sensors on 6 February and finalized the replacement sensor's settings on 7 February 2016 at 03:41 UTC; it operated well for the rest of the campaign. On 15 March 2016, at 11:12 UTC, the solar panel providing power for the datalogger failed. It took about $18 \mathrm{~h}$ to diagnose the problem, find a replacement power supply and install it, and restart the surface station.

The surface observations were critical for the initialization of the radiosondes, so the surface station had to be located near the radiosonde release location, i.e., close to the bungalow housing the radiosonde data system. The surface station was originally set up on a grassy area northeast of the concrete pad. This location looked good at first, but after a few days of operations the staff realized that the anemometer sometimes spun in circles, indicating swirling winds; that the range of recorded $(2 \mathrm{~min}$ ) wind directions was quite narrow; and that recorded winds were sometimes inconsistent with the values reported by the radiosondes after they had risen above the bungalows and trees. The surface station was moved to a better location, at the edge of the beach and further from all the bungalows, on 5 February 2016 (21:0022:00 UTC).

On 11 February 2016, at 04:05:43 UTC, four changes were made to the datalogger program. The execution interval, which determines how often each instrument is read, was changed from 2 to $1 \mathrm{~s}$. The internal offset for the barometer was changed from 599.5 to 399.5 , so that pressure would be reported with a resolution of $0.01 \mathrm{hPa}$ instead of $0.1 \mathrm{hPa}$. The averaging time was changed from 2 min to the more standard $1 \mathrm{~min}$. All these changes were made to give better data to help with radiosonde surface initialization and with data evaluations.

The failure of the T/RH sensor, the station move, the change to the datalogger software, and the failure of the datalogger power supply all caused gaps in the data (Table 3 ). We have not attempted to interpolate across any of the data gaps,

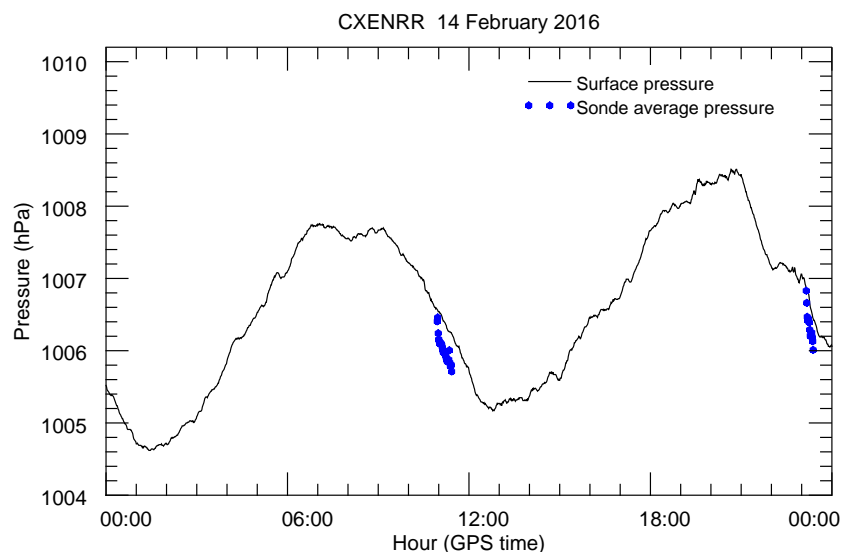

Figure 6. Surface pressure measured at Kiritimati by the PTB101B (1 min resolution) on 14 February 2016 together with pressures measured by the day's two radiosondes prior to launch ( $1 \mathrm{~min}$ averages). The first two points of the averaged radiosonde data are omitted; one is a partial average beginning just after the radiosonde was powered up on the battery, and the second was from inside the room rather than outdoors on the datalogger box.

nor have we tried to interpolate the $2 \mathrm{~min}$ data to $1 \mathrm{~min}$ values. Instead we have carefully examined data recorded before and after instrument moves, failures, and replacements, and have replaced suspicious data with the flags used to indicate missing data.

There is one final general note about the surface meteorology data. The radiosonde system maintains time very accurately, but it does so by getting the time from GPS satellites. The DigiCORA sounding software (Vaisala Oyj, 2010; version 3.64.1) sets the computer clock to GPS time, which was $17 \mathrm{~s}$ ahead of UTC time during ENRR, and the Campbell software sets the datalogger clock to the computer's time. For the final Kiritimati surface data set, all times have been shifted by $17 \mathrm{~s}$, so that all observations are reported in UTC.

\subsubsection{Surface pressure}

The radiosonde ground-check procedure requires an external pressure reading to provide a calibration check and correction to the radiosonde pressure sensor. This was provided by the Vaisala PTB101B pressure sensor mounted at 
(a)

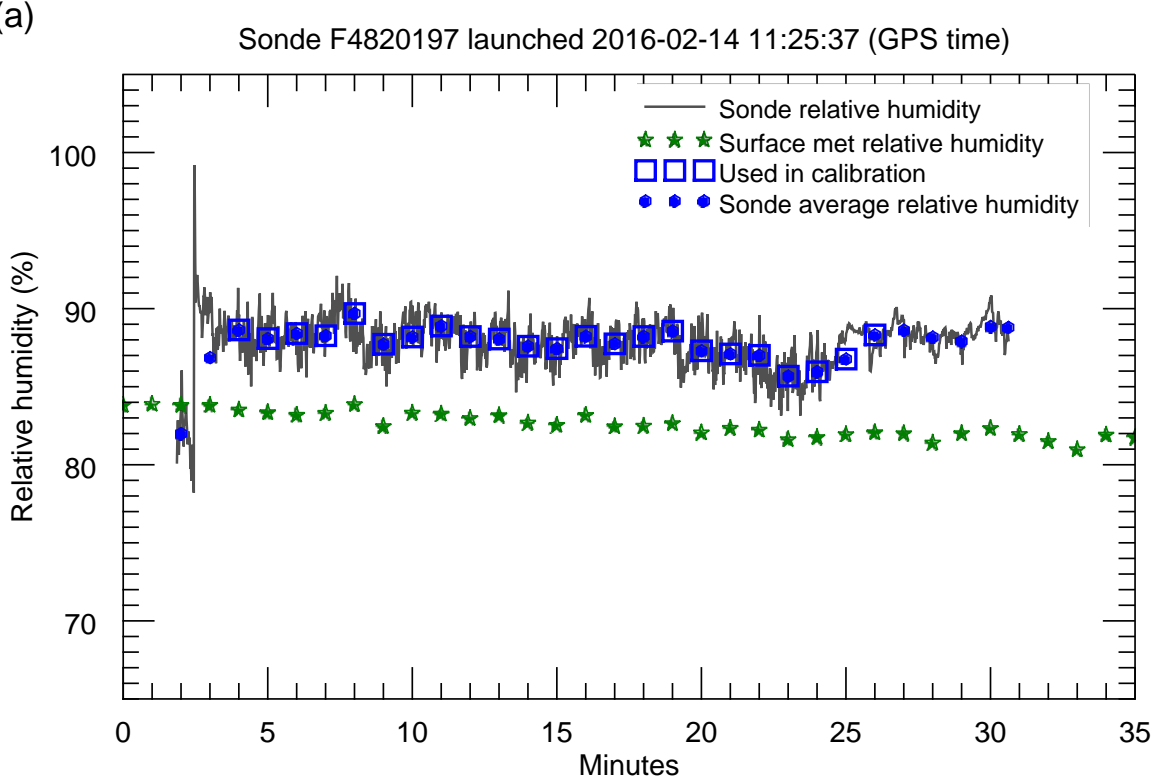

(b)

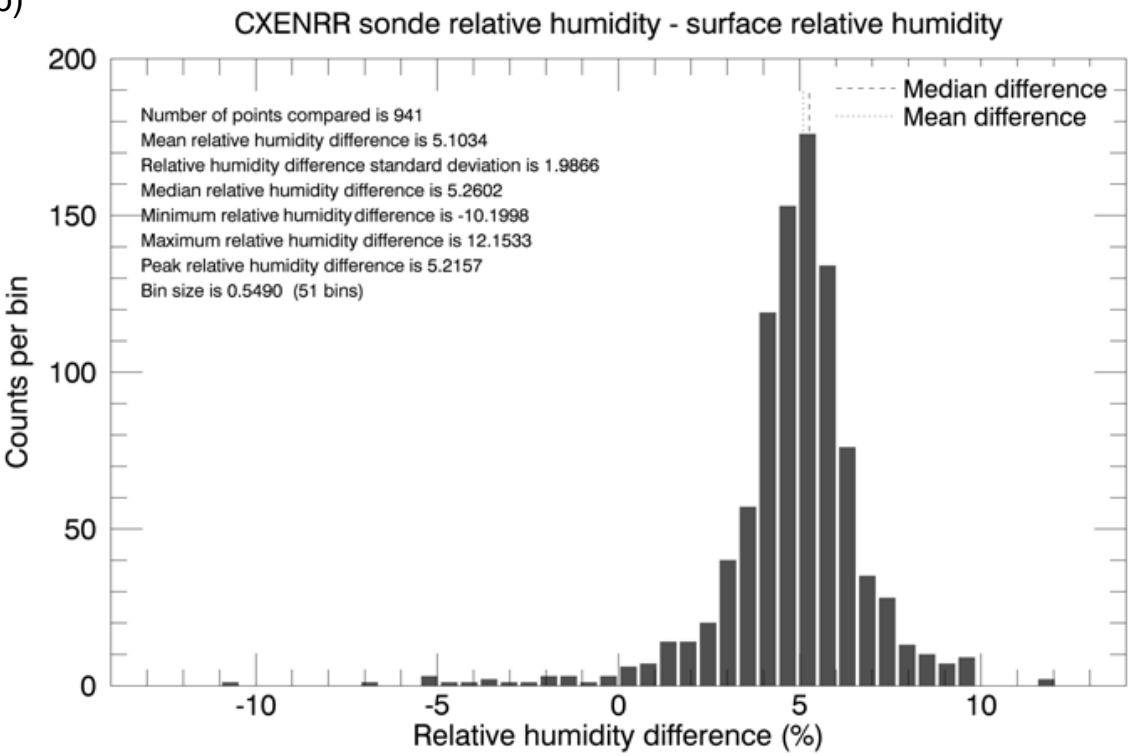

Figure 7. (a) $1 \mathrm{~s}$ radiosonde relative humidity and $1 \mathrm{~min}$ average radiosonde relative humidity prior to the 14 February 2016, 12:00 UTC launch at Kiritimati, together with 1 min values of HMP45C relative humidity. The initial portion of the radiosonde data covers the period when the radiosonde was transported from the Vaisala GC25 ground-check unit inside the bungalow out to the surface station. The averaged values from this radiosonde that were part of the set used to calibrate the surface humidity instrument are indicated. (b) Differences between $1 \mathrm{~min}$ average radiosonde humidities and $1 \mathrm{~min}$ values of relative humidities from the HMP45C when the radiosonde was co-located with the Kiritimati surface instruments prior to launch. All available good surface data and the corresponding radiosonde data (101 radiosondes) are included.

$3.6 \mathrm{~m}$ a.s.l. on the instrument tripod. The barometer was installed with a Vaisala SPH10 static pressure head to minimize wind-induced errors. During the first month of the experiment, the staff noted pressure differences between the PTB101B and both the radiosondes (Fig. 6) and other barometers. The PTB101B was checked against a high-quality calibrated standard after returning to Colorado. The PTB101B read $0.64 \mathrm{hPa}$ too high, so in the final data set all the surface pressure data were decreased by $0.64 \mathrm{hPa}$ to account for this calibration offset. 

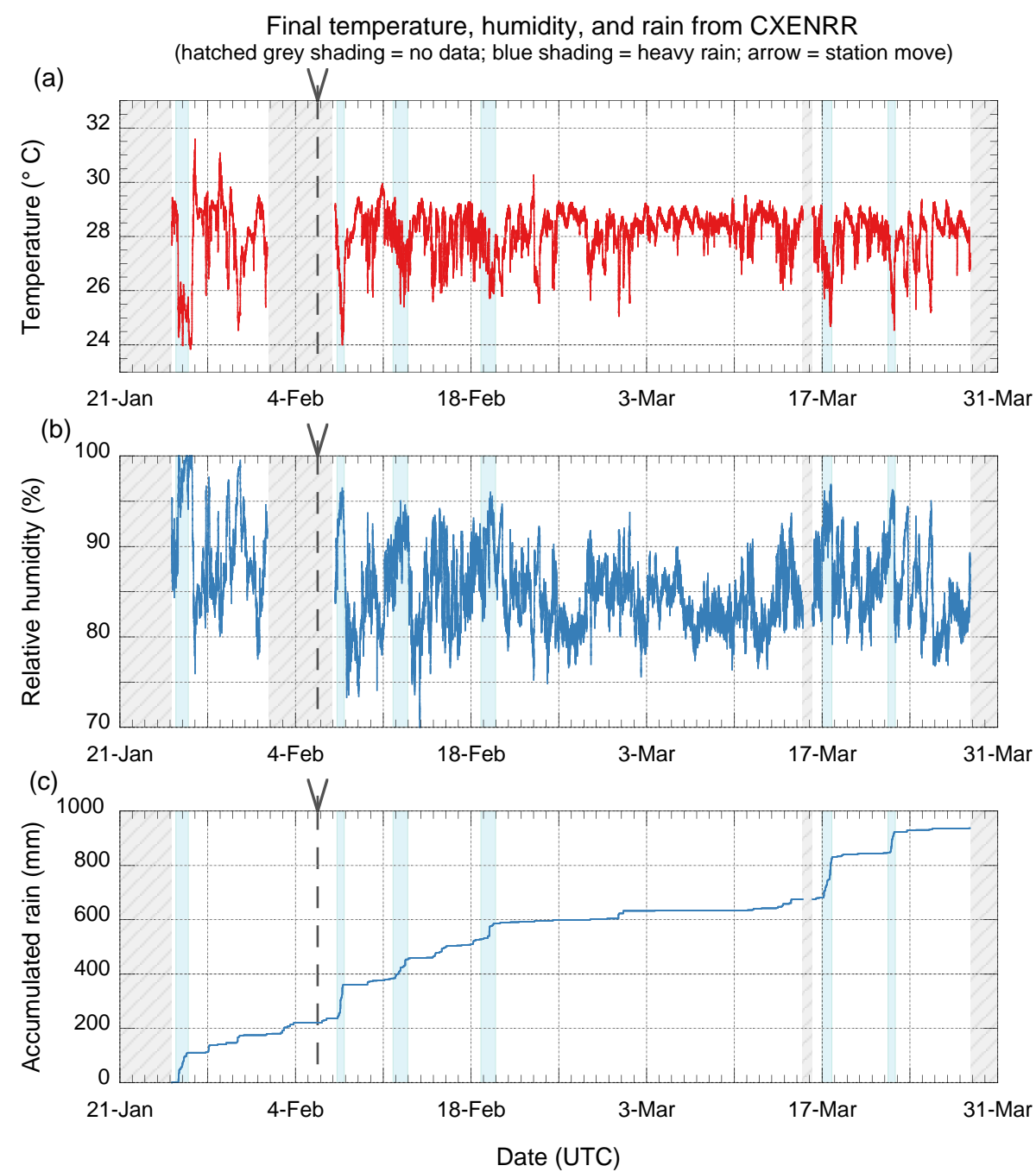

Figure 8. The final time series of temperature (a) and relative humidity (b) from Kiritimati Island, together with the accumulated rainfall (c) during the deployment. Pale blue shading indicates the six largest rainfall events, and is repeated on all graphs for reference, while hatched grey shading indicates times with no data.

\subsubsection{Relative humidity and temperature}

The radiosonde ground-check procedure serves to calibrate each radiosonde's humidity sensor, so we considered that to be our most trustworthy source of humidity information. In light of that, it became obvious very early in the project that there were problems with the station's original HMP45C humidity probe. These were not entirely solved by the replacement HMP45C. Figure 7a shows the HMP45C humidity readings with the co-located radiosonde data before the 14 February 2016, 12:00 UTC launch. This was a very typical situation, with the HMP45C consistently reporting lower humidity than the radiosonde. Analysis of all co-located data collected after the HMP45C was replaced shows that the mean difference between the HMP45C and the co-located radiosonde humidity was $5.1 \%$ (Fig. $7 \mathrm{~b}$ ). We have therefore corrected the surface relative humidity for this bias by adding
$5.1 \%$ to all reported relative humidity values that were considered good. (Put another way, we calibrated our replacement HMP45C against a sequence of calibrated radiosonde humidity sensors.) The final values are shown in Fig. 8 b.

During post-deployment evaluation of our data, we also compared the 1 min HMP45C temperature with $1 \mathrm{~min}$ averages of radiosonde temperatures collected while the radiosonde was co-located with the instrument tripod. All comparisons are with the replacement sensor. The results (Fig. 9) show that the mean temperature difference between the radiosonde temperatures and those from the HMP45C is less than $\pm 0.1{ }^{\circ} \mathrm{C}$. This is better than expected, given the differences of shielding and aspiration ${ }^{3}$. We concluded that the

\footnotetext{
${ }^{3}$ The HMP45C was inside a radiation shield, while the radiosonde was merely set in the shade of the solar panel. Neither the HMP45C nor the radiosonde was mechanically aspirated. The
} 


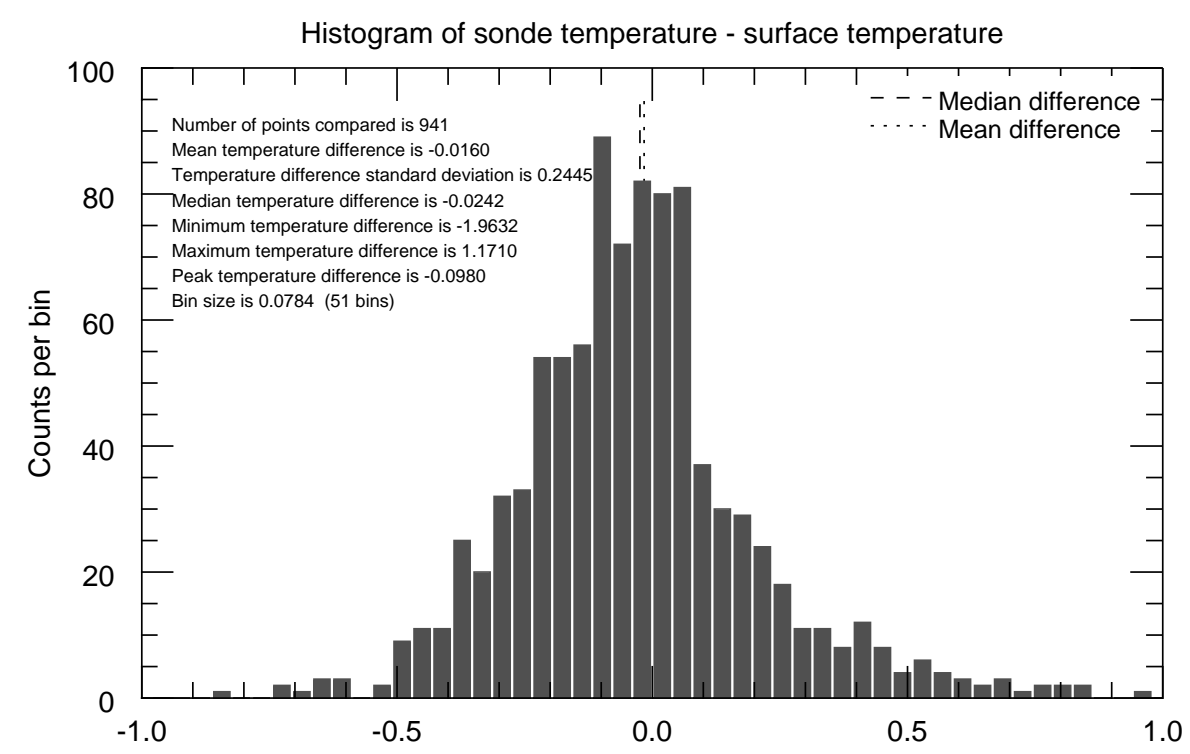

Figure 9. Differences between 1 min average radiosonde temperatures and 1 min values of temperatures from the HMP45C when the radiosonde was co-located with the Kiritimati surface instruments prior to launch. All available good surface data and the corresponding radiosonde data (101 radiosondes) are included.

temperature probe data, except for the initial deployment period when there was a bad probe, could be used as recorded in the field. Figure 8 a shows the final time series.

\subsubsection{Winds}

Several hours after initial setup the base of the anemometer was aligned to face south using a Brunton hand-held compass. The user was standing within a few meters of the tripod and the anemometer was $3.88 \mathrm{~m}$ above ground level. Wind observations prior to this are of speed only. The alignment was repeated when the station was relocated. On 28 March 2016 the on-site observers used a hand-held compass and string to determine whether the anemometer was aligned at $168^{\circ}$ relative to magnetic north, within a $\pm 3^{\circ}$ range. Since the declination for our site is $9.03^{\circ}$ east of north (National Centers for Environmental Information, 2016), the values recorded on site will show a $180^{\circ}$ wind direction when the wind is $168^{\circ}+9^{\circ}=177^{\circ}$. We have therefore subtracted $3^{\circ}$ from the recorded wind directions to correct for this bias. This correction was applied to the entire record, since the alignment method was the same during initial deployment and after the move. The measured wind speeds are the best estimate we have of the actual wind speeds, and we have not changed them. The final time series is shown in Fig. 10.

As mentioned above, neither the initial nor final location of the surface instruments was ideal from a wind perspective.

radiation shield is designed to allow aspiration by the ambient airflow, but we do not assume that the effects of air flow through the shield and air flow over the exposed radiosonde sensors were the same.
The bungalows were approximately $6 \mathrm{~m}$ high, and no place near our launch site qualified as "open terrain", i.e., with "the distance between the anemometer and any obstruction ... at least 10 times ... the height of the obstruction" (World Meteorological Organization, 2013, Part III Sect. 3.3.5). Therefore, even after the move there were still blockage issues affecting the measured winds. However, moving the station clearly increased the range of wind directions and speeds we observed. We have analyzed the corrected winds over several time periods, calculating various statistics from the highresolution time series and also evaluating the directions in both 5 and $10^{\circ}$ bins $^{4}$. Before the move, the mean wind speed was $2.23 \mathrm{~m} \mathrm{~s}^{-1}$ with a mean direction of $22.5^{\circ} ; 71 \%$ of the winds came from 0 to $50^{\circ}$ (Fig. 11a), with very small secondary clusters from the south $\left(160-180^{\circ}, 5 \%\right)$ and southwest $\left(230-275^{\circ}, 7 \%\right)$. Only $3.4 \%$ of the measured winds were from the $50-160^{\circ}$ sector, which is surprising considering Kiritimati's location in the trade wind region. After the move, the mean wind speed was $4.52 \mathrm{~m} \mathrm{~s}^{-1}$ and the mean direction $61.9^{\circ} ; 85 \%$ of the winds came from 15 to $100^{\circ}$ (Fig. 11b), with large clusters at $50-70^{\circ}(28 \%)$ and $80-95^{\circ}$ $(19 \%)$. Winds from the remainder of the $50-160^{\circ}$ sector, i.e., from 100 to $160^{\circ}$, were uncommon (4\%), while extremely small but distinct secondary clusters were still present from the south $\left(175-195^{\circ}, 2 \%\right)$ and southwest $\left(240-265^{\circ}, 1 \%\right)$.

Statistical analysis of the station move's impact, e.g., whether or not the winds are different before and after the

\footnotetext{
${ }^{4}$ The $10^{\circ}$ bins provide a representative visual summary of the slightly more nuanced view the $5^{\circ}$ bins show, so we present figures using $10^{\circ}$ bins accompanied by quantitative discussion from the $5^{\circ}$ binned data.
} 

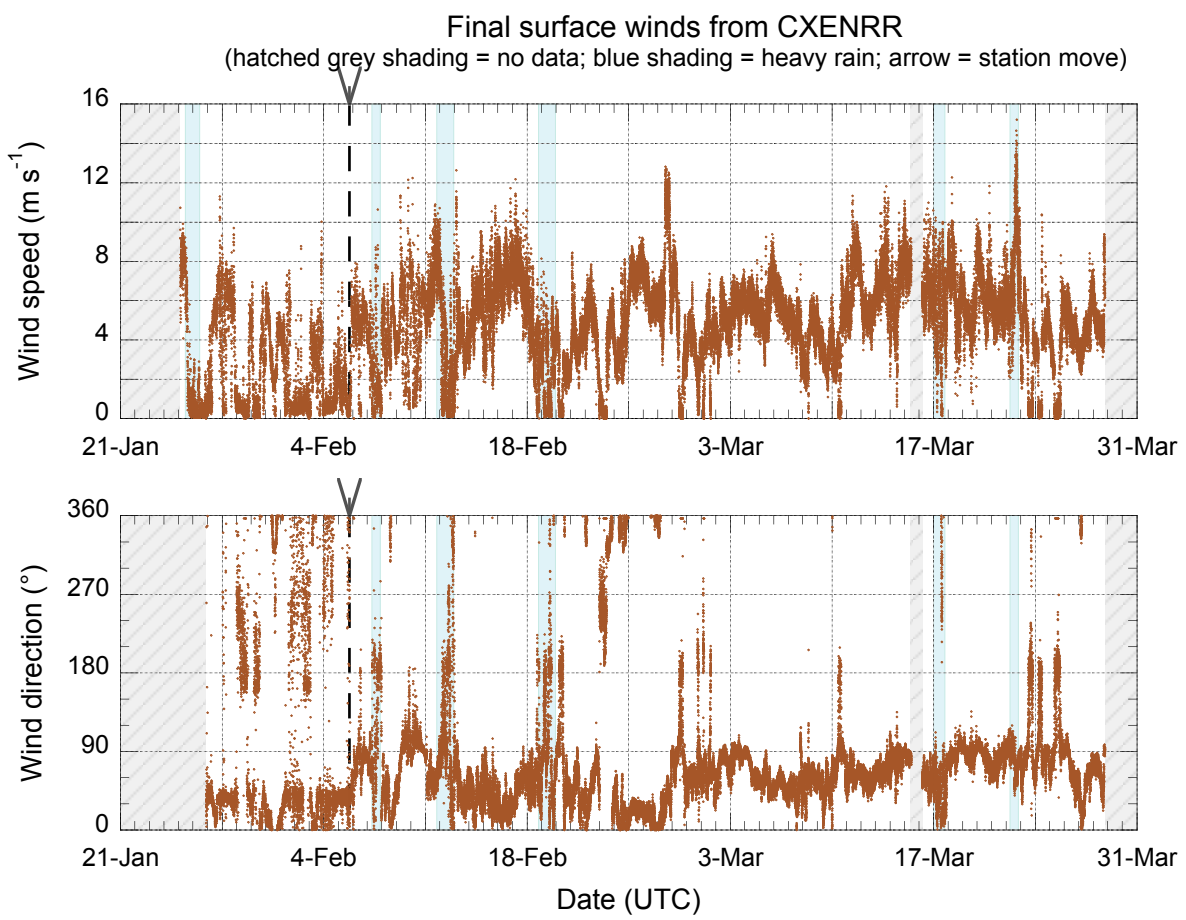

Figure 10. The corrected surface winds from the Kiritimati Island site. Pale blue shading indicates the six largest rainfall events (cf. Fig. 8), while hatched grey shading indicates times with no data.

\section{CXENRR wind direction}

(a) All data before station move ( 10 days)

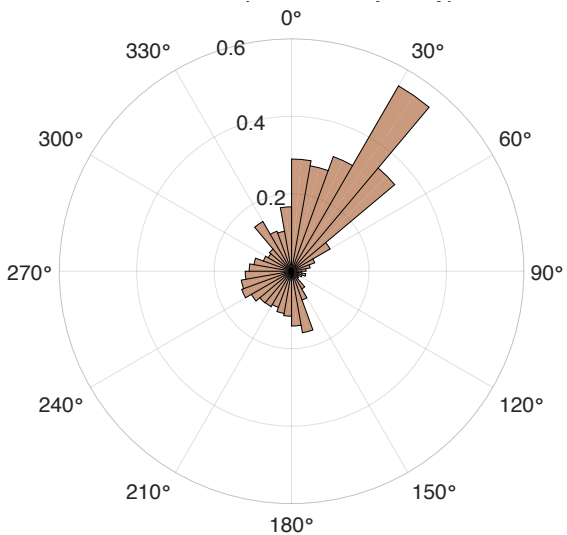

(b) All data after station move ( $\sim 52$ days)

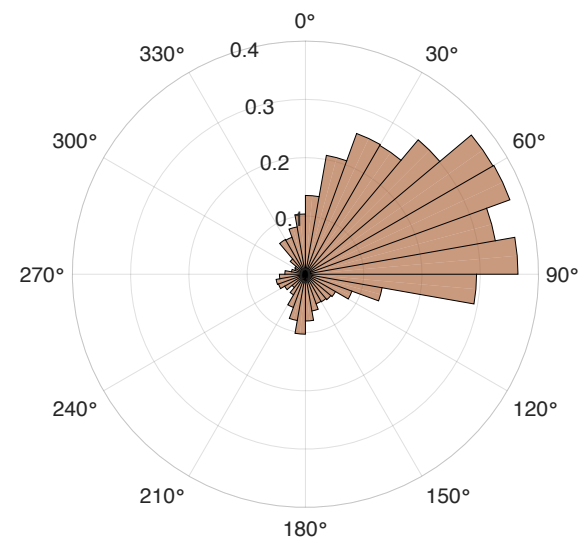

Figure 11. Rose diagrams of all data collected before (a) and after (b) the CXENRR station was moved on 5 February 2016. Sector lengths are proportional to the square root of the relative frequency of that $10^{\circ}$ bin, so the area of each sector is proportional to that bin's frequency. All data before the move are 2 min averages; there are about 5.25 days of such data after the move, and thereafter the data are 1 min averages.

move, is complicated both by the very unequal lengths of the "before" and "after" periods (and the attendant possible large-scale meteorological variations) and by the change in averaging period on 11 February 2016. We have therefore formally compared the 5.25 days' worth of 2 min winds available after the move with 5.25 days' worth of winds immediately before the move. Our analysis employs circu- lar statistics; it follows Fisher (1995) and relies heavily on MATLAB routines described by Berens (2009). Rose diagrams from these equal before and after periods are shown in Fig. 12, key statistical quantities in Table 4, and calculation details in Appendix A. The before and after wind roses show many of the same features noted in Fig. 11, and Fig. 10 shows that the 5.25 days immediately after the move incor- 
Table 4. Circular statistics computed from 5.25 days' worth of 2 min average CXENRR winds collected immediately before (left) and after (right) the CXENRR station was moved on 5 February 2016. The $3^{\circ}$ directional correction discussed in Sect. 3.1.3 was applied before statistics were calculated. Statistical definitions are given in Appendix A1.

\begin{tabular}{|c|c|c|}
\hline Parameter & $\begin{array}{c}\text { Before } \\
\text { (31 January 2016, 15:19:43 UTC- } \\
5 \text { February 2016, 21:19:43 UTC) }\end{array}$ & $\begin{array}{c}\text { After } \\
\text { (5 February 2016, 22:03:43 UTC- } \\
\text { 11 February 2016, 4:03:43 UTC) }\end{array}$ \\
\hline Number of observations $n$ & 3780 & 3765 \\
\hline Mean direction $\bar{\theta}$ & $18.8^{\circ}$ & $81.1^{\circ}$ \\
\hline Mean resultant length $\bar{R}$ & 0.63 & 0.77 \\
\hline Median direction $\widetilde{\theta}$ & $302.0^{\circ}$ & $86.6^{\circ}$ \\
\hline Circular dispersion $\hat{\delta}$ & 0.54 & 0.45 \\
\hline Concentration parameter $\hat{\kappa}$ & 1.65 & 2.56 \\
\hline & \multicolumn{2}{|c|}{ Summary } \\
\hline$\hat{\delta}_{\max } / \hat{\delta}_{\min }$ & \multicolumn{2}{|c|}{1.2} \\
\hline Test statistic $Y_{2}$ & \multicolumn{2}{|c|}{4262.4} \\
\hline
\end{tabular}

\section{CXENRR wind direction}

(a) Before station move (5.25 days)

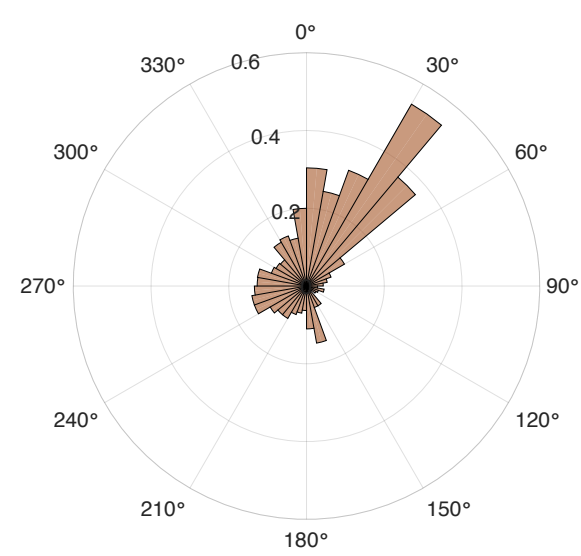

(b) After station move (5.25 days)

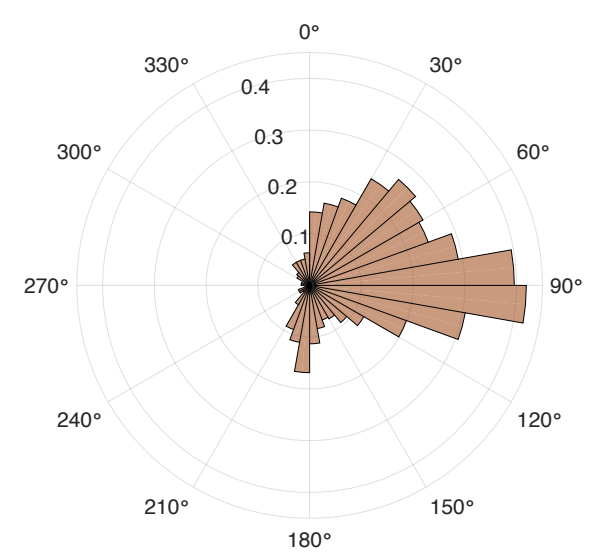

Figure 12. Rose diagrams of 5.25 days' worth of 2 min averages collected immediately before (a) and after (b) the CXENRR station was moved on 5 February 2016. Sector lengths are proportional to the square root of the relative frequency of that $10^{\circ}$ bin, so the area of each sector is proportional to that bin's frequency.

porate variability similar to the full "after" time series. The null hypothesis that the mean directions are the same is to be rejected if the test statistic $Y_{r}$ is too large when compared to the upper $100(1-\alpha) \%$ point on a $\chi_{v}^{2}$ distribution with $v=r-1$ degrees of freedom. In this case $r=2$, and $Y_{2}$ far exceeds the threshold needed to reject the null hypothesis at the $0.1 \%$ significance level.

\subsection{NOAA Ship Ronald H. Brown}

Post-processing and quality control of the surface data recorded on NOAA Ship Ronald H. Brown made use of the ship's occasional proximity to TAO buoys that were actively collecting data (generally the buoys were offline for maintenance when the ship was nearby), and also took advantage of equipment associated with our radiosonde launches. Before launch the Vaisala RS92-SGP radiosondes were put through a ground-check process inside an air-conditioned space. Because the final surface meteorology data would be needed for the post-processed radiosonde data, some of these ship observations have been adjusted to the height of the Vaisala GC25 ground-check set (3.8 $\mathrm{m}$ a.s.l.).

\subsubsection{Station pressure}

Atmospheric pressure was measured with a Vaisala PTB330 which had been calibrated on 29 December 2015. While the barometer was located on the ship's bridge (15.24 ma.s.1.) the pressure reported in the data set has been adjusted to 


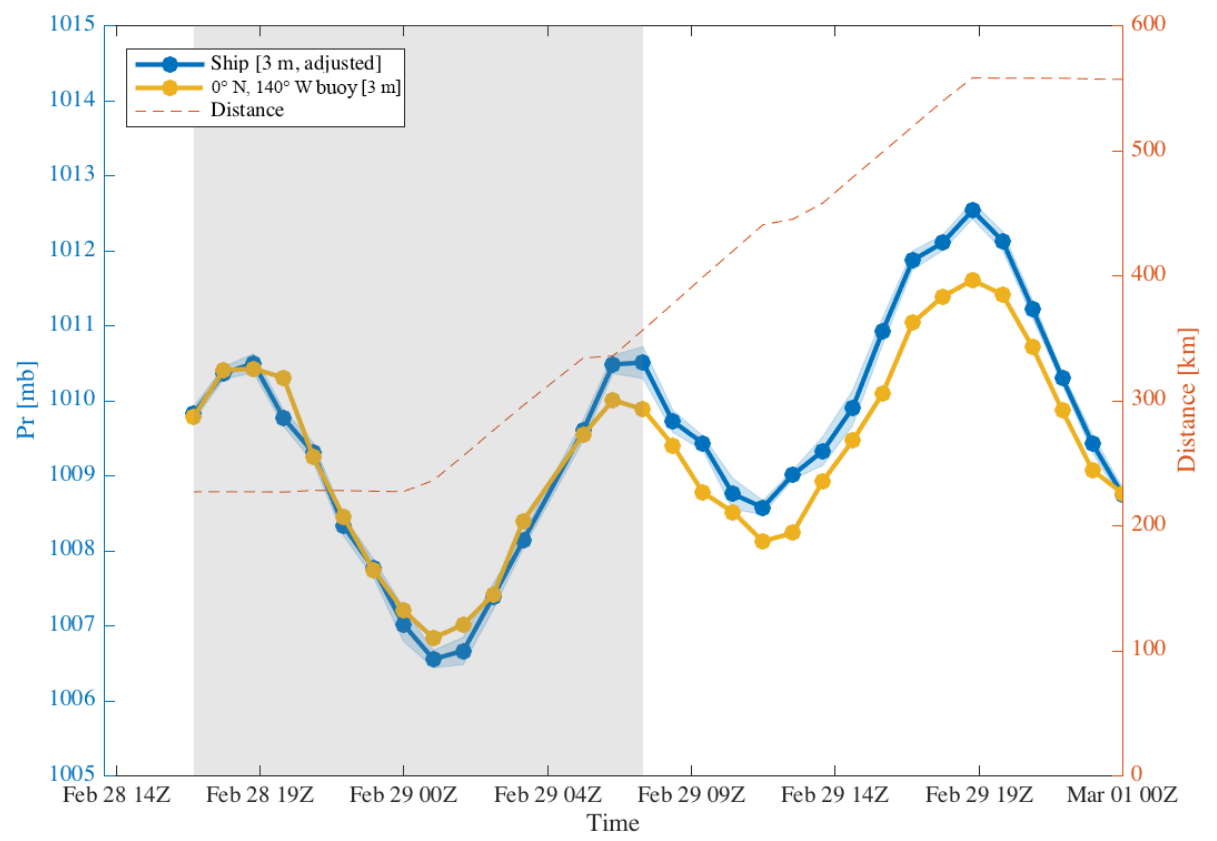

Figure 13. Barometric pressure at $3 \mathrm{~m}$ a.s.1. from the ship (blue) and from buoy dm166b (yellow), 28 February through 1 March 2016 . Each observation is a $2 \mathrm{~min}$ average centered on the top of the hour. Blue shading shows the $1 \sigma$ variability of the 2 min average from the ship; this information is not available from the buoy. The red-dashed line shows the distance between the ship and the buoy in kilometers. For the time period when the ship was $<350 \mathrm{~km}$ from the buoy (grey shading), the difference (ship minus buoy) is $-0.03 \pm 0.3 \mathrm{hPa}$.

$3.8 \mathrm{~m}$, the height of the Vaisala GC25 ground-check set, via the hypsometric equation.

The ship's pressure sensor is mounted on the port side of the bridge. Airflow distortion caused by the superstructure of the ship can result in localized pressure anomalies. We compared the ship pressure with the pressure observed by the radiosondes while the radiosondes equilibrated outside on the fantail of the ship (see Hartten et al., 2018). This analysis revealed a bias in the ship pressure as a function of relative wind direction that is approximately $0.007 \mathrm{hPa}$ per degree of relative wind direction $(r=-0.46, p<0.001)$ : positive when the winds are incident upon the port side, negative when they are incident upon the starboard side, and near zero when the relative wind direction is aligned along the ship's length. However, while a correction improves the overall statistical bias of the data set, it introduces discontinuities into the time series when applied to these high temporal resolution data. Therefore, the uncertainty is reported here and a correction was applied to the pressures that were input as surface observations for the soundings, but no such correction was applied to the $1 \mathrm{~min}$ average pressure in the surface data set.

The TAO buoy at $0^{\circ} \mathrm{N}, 140^{\circ} \mathrm{W}(\mathrm{dmb} 166)$ reports atmospheric pressure at the top of every hour using a Paroscientific MET1 pressure sensor mounted at $3 \mathrm{~m}$ (National Data Buoy Center, 2010a, b). Unfortunately, when the ship arrived on location we discovered that dmb166 was damaged, so no data are available during our approach. The closest overlapping pressure observations are from after the buoy was repaired, on 28 and 29 February 2016 while the ship was traveling south but still within several hundred kilometers of the buoy. Comparing the ship pressure, adjusted to the buoy pressure sensor height of $3 \mathrm{~m}$ a.s.l., and the buoy pressure during this time (Fig. 13) shows that the two were in close agreement from when the buoy pressure becomes available until around 06:00 UTC on 29 February when the two measurements began to diverge systematically, likely because of the large distance between the sensors (more than $350 \mathrm{~km}$ after 07:00 UTC on 29 February). From 14:00 UTC on 28 February through 07:00 UTC on 29 February the mean and standard deviation of the difference (ship minus buoy) is $-0.08 \mathrm{hPa} \pm 0.24 \mathrm{hPa}$.

\subsubsection{Temperature}

Atmospheric thermodynamic temperature was measured at $1 \mathrm{~Hz}$ by an IMET Rotronic MP-101A mounted on the bow mast at approximately $15 \mathrm{~m}$ a.s.l. The sensor, which has been modified by Woods Hole Oceanographic Institution (WHOI, 2010a, b), was last calibrated on 26 July 2014. Most TAO buoys record temperature, so the ship's air temperature can be validated against many measurements made away from the superstructure of the ship. The buoys record temperature at $3 \mathrm{~m}$ a.s.l. using Rotronic MP-101A temperaturehumidity probes (National Data Buoy Center, 2010a, b). Buoy measurements are recorded every $10 \mathrm{~min}$ based on $2 \mathrm{~min}$ averages of $2 \mathrm{~Hz}$ measurements around the sample 

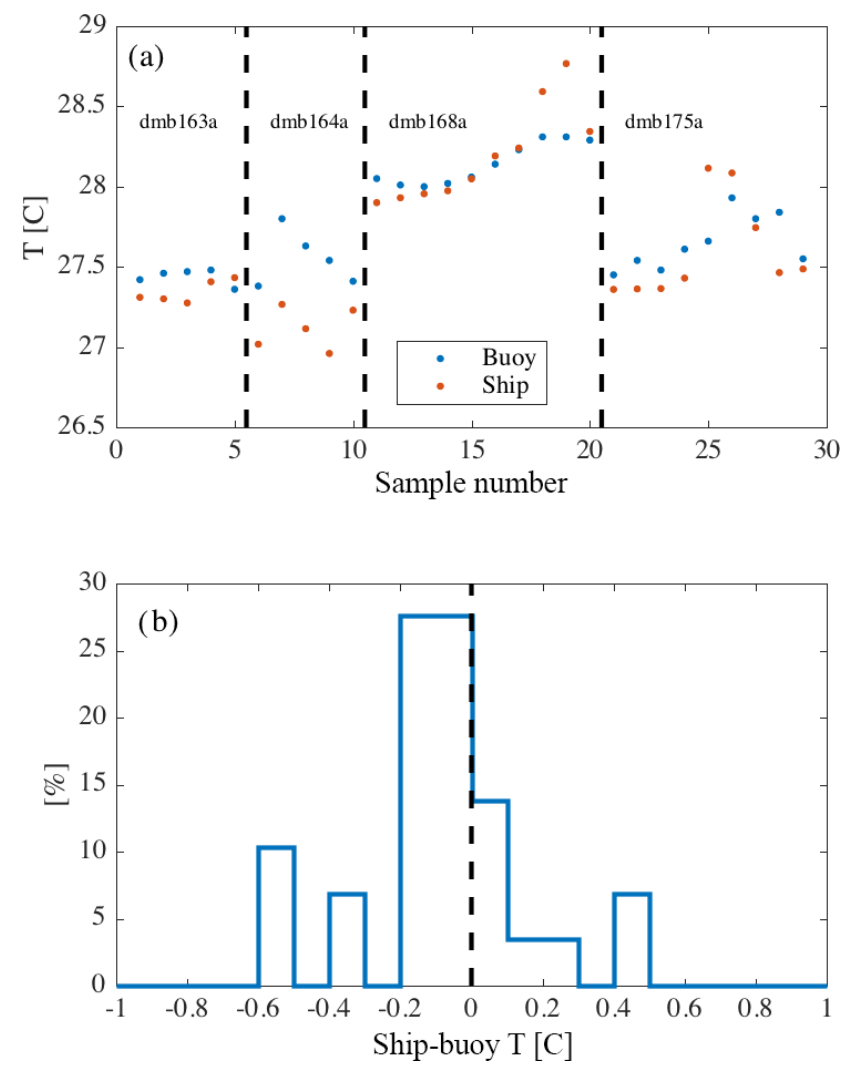

Figure 14. Comparisons between the air temperatures measured by the ship and by a buoy when the ship was within $0.1^{\circ}$ latitude/longitude of the buoy. All data are $10 \mathrm{~min}$ averages; ship measurements are from $15 \mathrm{~m}$ and buoy measurements from $3 \mathrm{~m}$ a.s.l. (a) All available observation pairs, with dashed vertical lines separating buoys: dmb163a $\left(9^{\circ} \mathrm{N}, 140^{\circ} \mathrm{W}\right), \mathrm{dmb} 164 \mathrm{a}\left(5^{\circ} \mathrm{N}, 140^{\circ} \mathrm{W}\right)$, dmb168a $\left(5^{\circ} \mathrm{S}, 140^{\circ} \mathrm{W}\right)$, and dmb175a $\left(8^{\circ} \mathrm{N}, 125^{\circ} \mathrm{W}\right)$. (b) The distribution of all differences between those pairs.

time. Figure 14 shows a comparison between the temperature from the bow mast, averaged to match to buoy sampling, and the temperatures reported from select buoys. Comparisons are only made when the ship was within $0.1^{\circ}$ latitude and $0.1^{\circ}$ longitude $(\sim 10-15 \mathrm{~km})$ of the buoy, i.e., on 29 occasions involving four buoys at $\left(9^{\circ} \mathrm{N}, 140^{\circ} \mathrm{W}\right),\left(5^{\circ} \mathrm{N}\right.$, $\left.140^{\circ} \mathrm{W}\right),\left(5^{\circ} \mathrm{S}, 140^{\circ} \mathrm{W}\right)$, and $\left(8^{\circ} \mathrm{N}, 125^{\circ} \mathrm{W}\right)$. The difference between the ship and buoy temperatures (ship minus buoy) is $-0.09^{\circ} \mathrm{C} \pm 0.25^{\circ} \mathrm{C}$, which is within the uncertainty in the sensor calibrations $\left(\sim 0.4^{\circ} \mathrm{C}\right)$. Note that this comparison is between temperatures observed at slightly different heights; for context, the average difference between the temperature observed at $15 \mathrm{~m}$ and $3 \mathrm{~m}$ from the 93 radiosondes was simi$\operatorname{lar}\left(-0.1{ }^{\circ} \mathrm{C} \pm 0.14^{\circ} \mathrm{C}\right)$.

\subsubsection{Relative humidity}

Atmospheric relative humidity $(\mathrm{RH})$ was also measured at $1 \mathrm{~Hz}$ by the IMET Rotronic MP-101A on the bow mast at
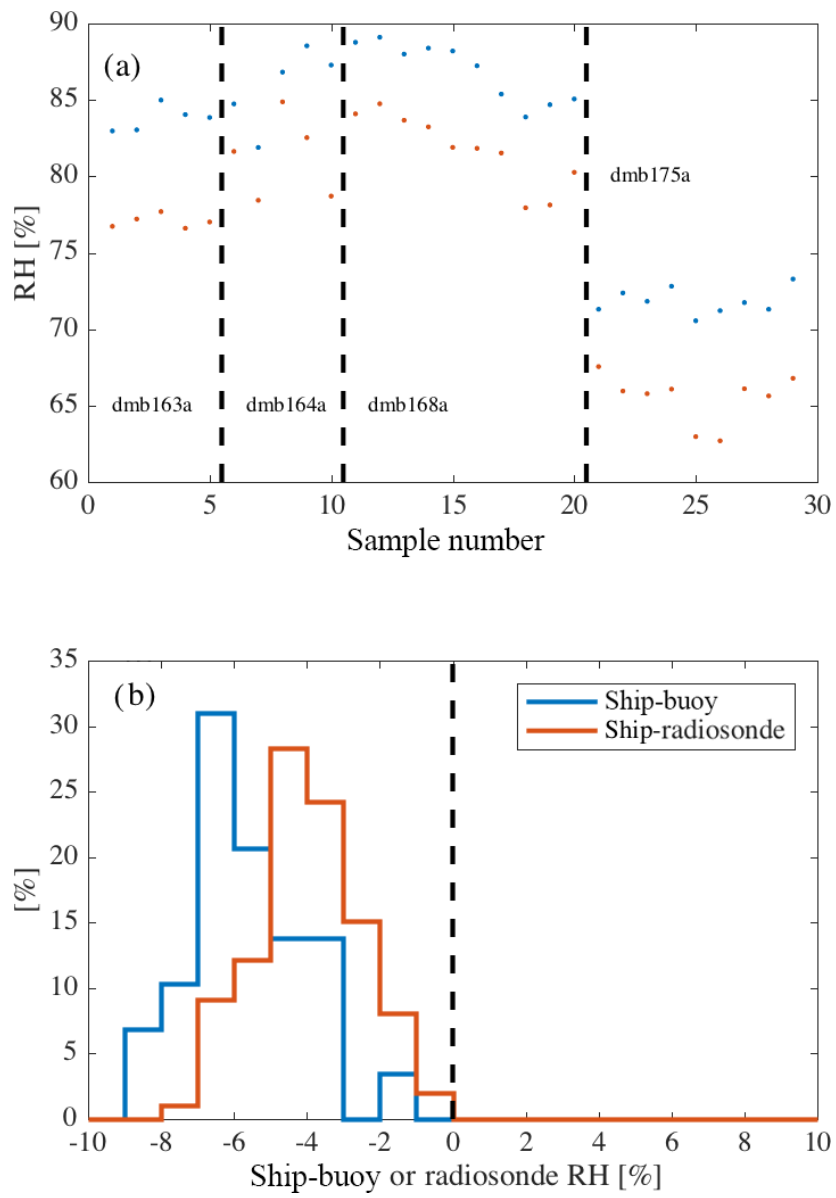

Figure 15. Comparisons between the $\mathrm{RH}$ measured by the ship and by a buoy when the ship was within $0.1^{\circ}$ latitude/longitude of the buoy. All data are $10 \mathrm{~min}$ averages; ship measurements are from $15 \mathrm{~m}$ and buoy measurements from $3 \mathrm{~m}$ a.s.l. (a) All available observation pairs, with dashed vertical lines separating buoys: dmb163a $\left(9^{\circ} \mathrm{N}, 140^{\circ} \mathrm{W}\right)$, dmb164a $\left(5^{\circ} \mathrm{N}, 140^{\circ} \mathrm{W}\right), \mathrm{dmb} 168 \mathrm{a}$ $\left(5^{\circ} \mathrm{S}, 140^{\circ} \mathrm{W}\right)$, and dmb175a $\left(8^{\circ} \mathrm{N}, 125^{\circ} \mathrm{W}\right)$. (b) The distribution of all differences between paired ship and buoy RHs, together with the differences between 99 pairs of ship $\mathrm{RH}$ and radiosonde $\mathrm{RH}$, the latter from $4 \mathrm{~m}$ a.s.l.

approximately $15 \mathrm{~m}$ a.s.l., and by Rotronic MP-101A probes mounted on the TAO buoys at $3 \mathrm{~m}$ a.s.l. We compared the ship RH and buoy RH for the same cases and using the same methodology as for temperature, with a different outcome (Fig. 15). There is a systematic bias of $-5.7 \% \pm 1.6 \%$ in the ship's RH observation compared to those from the buoys. Also plotted in Fig. 15b is a comparison between the ship $\mathrm{RH}$ and the humidity reported by radiosondes while they were outside on the fantail ( $\sim 4 \mathrm{~m}$ a.s.l.) prior to launch. The comparison was only made for radiosondes launched during night (solar zenith angle $>90^{\circ}$ ) because of solar heating of the fantail deck during the day (Hartten et al., 2018) and uses radiosonde data averaged over the 1 min just prior to launch. This comparison was again between two differ- 
ent heights, $\sim 15$ and $\sim 4$ ma.s.l. Edson et al. (2004) documented strong near-surface vertical humidity gradients at approximately $\left(3^{\circ} \mathrm{S}, 122\right.$ to $\left.150^{\circ} \mathrm{W}\right)$ during February 2001 , using measurements made from NOAA Ship Ronald $H$. Brown during GasEx-01, so we expect to see a difference of about $1.5 \%$. The actual difference between our nighttime radiosonde $\mathrm{RH}$ profiles at these heights $(15 \mathrm{~m}$ minus $4 \mathrm{~m})$ is $-1.6 \% \pm 1.5 \%$, consistent with this expectation. The shipto-radiosonde comparison indicates that the ship RH is biased low $(-4.0 \% \pm 1.4 \%)$. Note that sensor response times and mixing of the ambient air by the superstructure of the ship give reason to exercise caution with respect to these results. The results nevertheless are consistent with the interpretation of the observed bias being instrumental error that is not explained by differences in height. We have therefore corrected the ship's recorded RH by adding a constant $4.0 \%$ throughout the cruise, resulting in an $\mathrm{RH}$ for an effective height of approximately $3 \mathrm{~m}$. We chose to use the correction based on the comparison to the radiosondes instead of the buoys because the sample size is larger $(n=99)$ and covers a longer range of time, and because the distance between the sensors was always less than $100 \mathrm{~m}$. As noted in Sect. 3.1.2, the radiosonde humidity sensors were calibrated as part of the pre-launch procedure, so this correction can also be described as calibrating the bow mast's IMET Rotronic MP101A against a sequence of calibrated radiosonde humidity sensors.

\subsubsection{Winds}

Wind speed and direction during the cruise were measured by sonic anemometers mounted on poles on both the port and starboard sides of the bridge roof, roughly $19 \mathrm{~m}$ a.s.l. Three issues affected the measurements, one particular to this cruise and the others more general: one of the bridge anemometers was misaligned; flow is distorted when an anemometer is in the lee of local obstacles; and the ship itself causes distortion of the wind flow at all points. Our corrections were complicated by the fact that the bow mast's anemometer was not operating and the ship was never co-located with a buoy that was collecting winds, both of which deprived us of independent measurements. The procedure we used to obtain what we consider to be a credible time series of wind speed and direction is described below.

We began by addressing the misaligned anemometer. After the field campaign was over we investigated this bias by examining the distribution of the differences in the wind direction when the wind speeds are in agreement and greater than $10 \mathrm{~m} \mathrm{~s}^{-1}$ while the ship-relative wind direction recorded by the port sonic was between 320 and $360^{\circ}$. The latter condition ensures that winds are from the port-side bow, since initial analysis indicated possible obstruction when winds were from 0 to $45^{\circ}$. The results indicate that the starboard sonic was misaligned $-17.6^{\circ}$ relative to the port sonic measurement, which is assumed to be properly aligned parallel to the
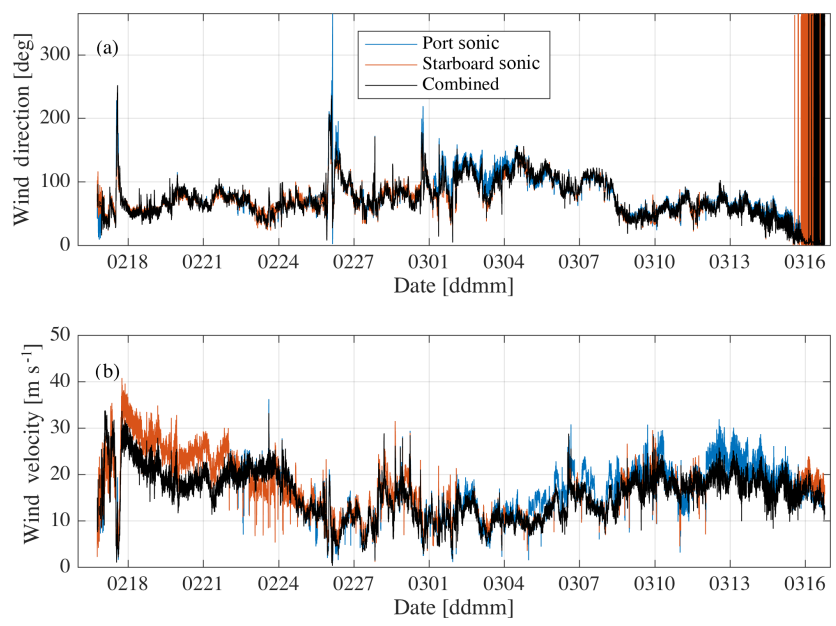

Figure 16. (a) Time series of wind directions during the entire cruise, as measured by the port side and starboard side ultrasonic anemometers and the time series constructed by combining the two. These winds have not been corrected for flow distortion. (b) Same as in (a), but for wind velocity.

ship's beam with "north" pointing in the direction of the bow. Therefore, all starboard sonic wind directions have been rotated clockwise by $17.6^{\circ}$, and all further discussion of starboard winds is based on the rotated values.

We next combined data from the two bridge anemometers into a single time series by selecting the windward anemometer at all times. Specifically, we used the starboard anemometer when it measured ship-relative winds between 0 and $170^{\circ}$ and the port anemometer when it measured shiprelative winds between 190 and $360^{\circ}$. When both were within range, the starboard anemometer's winds were used because our analysis of the data indicates there is less localized distortion near the starboard anemometer. When ship-relative winds were from the stern, which was quite rare, they were treated as missing. The resulting time series for the entire cruise is shown in Fig. 16.

The problems associated with free-stream velocity issues were addressed in multiple steps. The typical procedure would be to use the winds measured on the bow mast and correct for flow distortion at that position, which is well characterized for this vessel. Moat et al. (2001) used computational fluid dynamics simulations to calculate the biases in measured wind velocities due to flow distortions caused by NOAA Ship Ronald H. Brown's superstructure. They made calculations for sensor positions on the bow mast, but not for the anemometer positions on the bridge roof. However, even in the absence of calculations for the bridge positions, correction scale factors for an effective height in free stream for the sonic anemometers on the bridge could be estimated from a comparison to the corrected bow-mast wind measurements.

Since we had no bow-mast winds during ENRR, we instead estimated correction factors from data acquired by the 

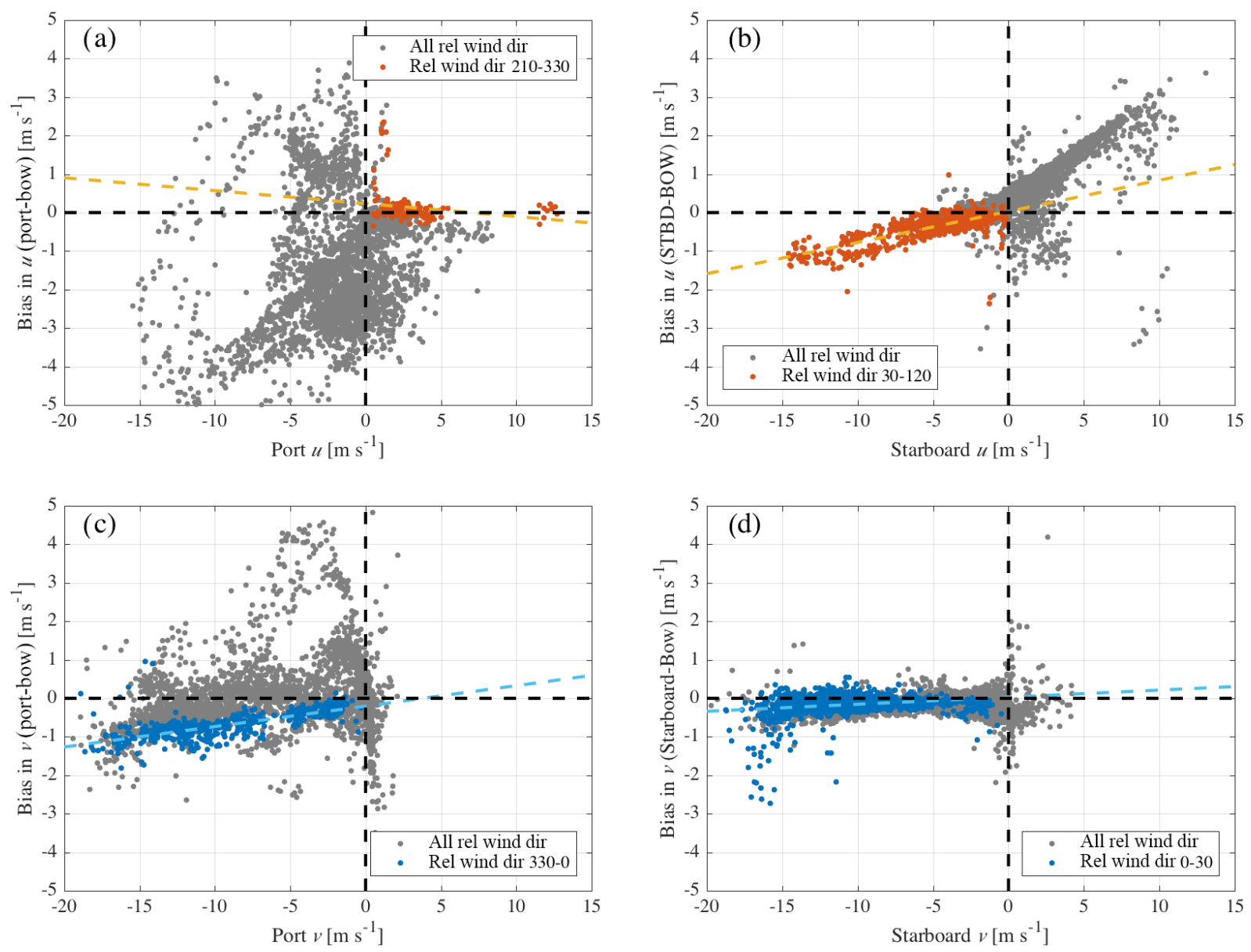

Figure 17. Comparisons between winds measured by the bridge sonic anemometers ("Port" and "Starboard") and the bow-mast anemometer ("Bow") on NOAA Ship Ronald H. Brown during CalWater-2, 2015. (a) The bias in $u$ (Port - Bow) as a function of observed wind speed at Port, (b) similar to (a), but for the Starboard sonic; (c) and (d) similar to (a) and (b) for the $v$ wind component. $u$ is defined perpendicular to the ship's orientation and $v$ is defined parallel.

Ronald H. Brown in January and February 2015 during the CalWater-2 field campaign. That cruise occurred in the Pacific, northeast of Hawaii (Ralph et al., 2016), and data from both bridge-mounted sonic anemometers and from a sonic anemometer mounted on the bow mast were recorded. We assume that the bias in the bow mast's sonic is $-5 \%$ in $v$ (parallel to the ship's orientation) and $+15 \%$ in $u$ (transverse to the ship's orientation) (Christopher Fairall and Byron Blomquist, personal communication, 2017) and incorporate correction factors accordingly for the CalWater-2 data. The biases in $u$ and $v$ for both of the bridge sonic anemometers are shown in Fig. 17 as functions of measured $u$ and $v$ at the bridge. These relationships are linear and so a single scale factor in $u$ and $v$, analogous to the corrections applied to the bow-mast data, can be used to correct the bridge data. The correction factors were determined using the mean proportional error (vertical lines in Fig. 18): $-6.1 \%$ (Port $v$ ), $+1.1 \%$ (Port $u$ ), $-2.7 \%$ (Starboard $v$ ), $-7.1 \%$ (Starboard $u$ ). These corrections effectively convert data from the bridge sonic anemometers to match the corrected winds measured by the sonic mounted on the bow, which is at a different height and is in a different position on the ship. Since the bow sonic anemometer is positioned at $17.251 \mathrm{~m}$, this becomes the effective height for the bridge sonic anemometer's data. We applied these correction factors to the wind data collected during ENRR at the bridge, and then scaled them assuming neutral stability conditions using the wind profile power law with an exponent of 0.11 (Hsu et al., 1994) in order to represent winds at the $3.8 \mathrm{~m}$ a.s.l. height of the GC25 ground-check set.

\subsubsection{Sea surface temperature, downwelling shortwave radiation, and ship position and movement}

SSTs were logged at $1 \mathrm{~Hz}$ from a Sea Bird SBE45 thermosalinograph operating at a depth of $5 \mathrm{~m}$. Downwelling shortwave radiation was logged at $1 \mathrm{~Hz}$ from an Eppley PSP. Latitude and longitude, as well as the ship's course and speed over ground, were recorded by a Furuno GP90, while ship 

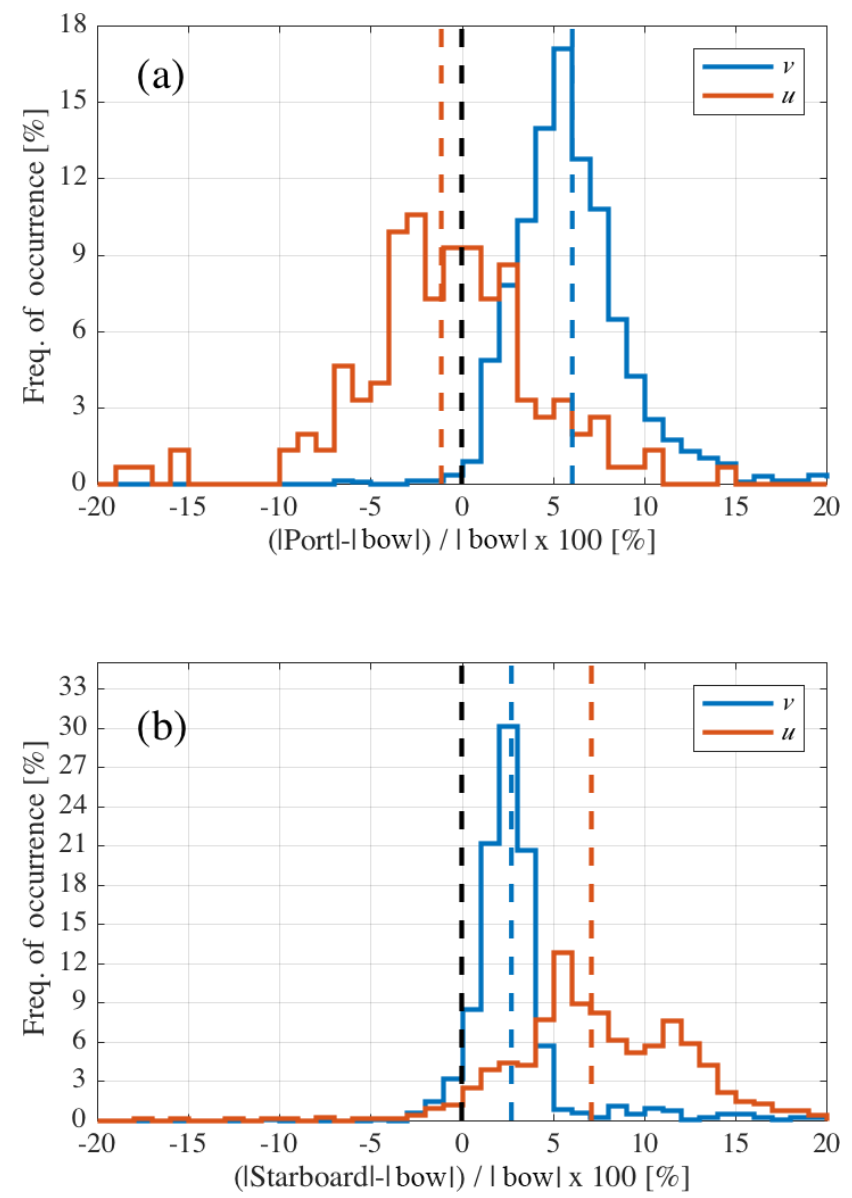

Figure 18. Distributions of the percent error in the (a) port and (b) starboard bridge sonic anemometers relative to the bow-mast sonic during CalWater-2. The data are the same as in Fig. 14, with $u$ defined as relative wind directions $210-330$ and $30-120^{\circ}$ and $v$ defined as relative wind directions $330-30^{\circ}$, but here they are shown normalized by wind speed to illustrate the source of the correction factors (denoted by the colored vertical-dashed lines) that are reported in the text.

heading was measured by a Sperry MK37, all at $1 \mathrm{~Hz}$. These collected data were averaged to $1 \mathrm{~min}$; no other changes were made.

\section{Surface fluxes at NOAA Ship Ronald $H$. Brown}

Based on the ENRR surface observations described in the previous section, we calculated bulk air-sea fluxes $(1 \mathrm{~h} \mathrm{av-}$ erages) using a recent version of the Tropical Ocean and Global Atmosphere (TOGA) Coupled Ocean-Atmosphere Response Experiment (COARE) flux algorithm (Fairall et al., 1996, 2003; most recently updated in Edson et al., 2013). These calculations include an estimate of the full surface heat budget (see Sect. 4.3). A complete list of the input data and the variables calculated from them by the COARE flux algorithm is in Table 5. The full COARE algorithm requires some atmosphere-ocean quantities that were not measured during the cruises. We have attempted to estimate radiative fluxes that were not measured directly using other variables that were, as described below, but some other variables such as rain rate and direct measurements of turbulent fluxes from eddy covariance methodology are not provided because the ancillary measurements are not available. However, bulk calculations of both latent and sensible heat fluxes are made using COARE and are provided (Table 5). The bulk calculations from COARE have been previously validated in the tropical ocean by comparison to direct measurements from eddy covariance (Fairall et al., 1996). Longwave downwelling radiation (LWD) is needed for the bulk flux calculations within the COARE algorithm if a cool-skin correction is applied to SST; it is required if a full surface heat budget is to be calculated from the COARE results. Unfortunately, LWD was not measured during this cruise and so we estimated it using other means, as described in Sect. 4.2.

\subsection{Treatment of measured properties}

We constructed $1 \mathrm{~h}$ average time series of several quantities needed as input by the COARE algorithm. These are all computed from the $1 \mathrm{~min}$ surface data set described in Sect. 3.2: atmospheric pressure ( $3.8 \mathrm{~m}$ a.s.1.); temperature $(15 \mathrm{~m})$; relative humidity (effective height $3 \mathrm{~m}$ ); wind speed (valid at $\sim 4$ ma.s.l.); ocean temperature (also known as SST, valid at $5 \mathrm{~m}$ depth); downwelling shortwave radiation; and latitude and longitude.

\subsection{Estimation of downwelling longwave radiation}

The LWD includes contributions from atmospheric gases and from clouds, and following convention we define those contributions as $\mathrm{LWD}_{\mathrm{clr}}$, the "clear-sky" flux from atmospheric gases only, and longwave cloud radiative effect (LWCRE), the enhancement to the LWD caused by clouds (e.g., McFarlane et al., 2013):

$\mathrm{LWD}=\mathrm{LWD}_{\mathrm{clr}}+\mathrm{LWCRE}$.

To determine LWD, we estimated LWD ${ }_{\text {clr }}$ and LWCRE from observations we did collect plus a number of simple assumptions, as described below. The values reported are referenced to the height of the Vaisala GC25 ground-check set, $3.8 \mathrm{~m}$ a.s.l.

We first used the longwave Rapid Radiative Transfer Model (RRTM, version 3.3; Mlawer et al., 1997) to calculate $\mathrm{LWD}_{\mathrm{clr}}$ from each atmospheric sounding collected during the cruise. At each sounding time we provided the model with the "Level 2" radiosonde temperature profile (Cox et al., 2017a) as well as with profiles of the seven most significant radiatively active gases: $\mathrm{H}_{2} \mathrm{O}, \mathrm{CO}_{2}, \mathrm{O}_{3}, \mathrm{~N}_{2} \mathrm{O}, \mathrm{CO}, \mathrm{CH}_{4}$, and $\mathrm{O}_{2}$. The profile of $\mathrm{H}_{2} \mathrm{O}$ came from the same radiosonde profile as the temperature. The $\mathrm{CO}_{2}$ was set to $398.4 \mathrm{ppm}$, which was the in situ monthly mean surface value measured 
Table 5. Variables, all at hourly resolution, contained in the surface flux data file. The RRTMv3.3 algorithm is described in Mlawer et al. (1997) and the coare35vnWarm algorithm in Edson et al. (2013). The height of the input winds, $3.8 \mathrm{~m}$ a.s.1., is denoted by $z_{u}$ and the Obukhov length by $L$.

\begin{tabular}{|c|c|c|c|}
\hline Description & Source & Abbreviation & Units \\
\hline \multicolumn{4}{|l|}{ Select input } \\
\hline Time & ship observations & Time (UTC) & days \\
\hline Year, month, day, hour, minute, second & ship observations & $\mathrm{Y}, \mathrm{M}, \mathrm{D}, \mathrm{h}, \mathrm{m}, \mathrm{s}$ & \\
\hline Latitude & ship observations & Lat & ${ }^{\circ} \mathrm{N}$ \\
\hline Longitude & ship observations & Lon & ${ }^{\circ} \mathrm{E}$ \\
\hline Atmospheric pressure corrected to $z_{u}$ & ship observations & $\mathrm{P}$ & $\mathrm{hPa}$ \\
\hline Sky cover & ship observations & SCV & \\
\hline Clear-sky longwave downward radiation & RRTMv3.3 & LWDclr & $\mathrm{W} \mathrm{m}^{-2}$ \\
\hline \multicolumn{4}{|l|}{ Surface energy budget } \\
\hline Longwave downward radiation at $z_{u}$ & calculated from $\mathrm{LWD}_{\mathrm{clr}}$, LWCRE & LWD & $\mathrm{W} \mathrm{m}^{-2}$ \\
\hline Longwave upward radiation & coare 35vnWarm & LWU & $\mathrm{W} \mathrm{m}^{-2}$ \\
\hline Shortwave downward radiation & ship observations & SWD & $\mathrm{W} \mathrm{m}^{-2}$ \\
\hline Shortwave upward radiation & coare35vnWarm & SWU & $\mathrm{W} \mathrm{m}^{-2}$ \\
\hline Bulk latent heat flux out of the ocean & coare $35 \mathrm{vnWarm}$ & hlb & $\mathrm{W} \mathrm{m}^{-2}$ \\
\hline Bulk sensible heat flux out of the ocean & coare 35 vnWarm & hsb & $\mathrm{W} \mathrm{m}^{-2}$ \\
\hline Bulk buoyancy flux into the ocean & coare $35 \mathrm{vnWarm}$ & $\mathrm{hbb}$ & $\mathrm{m}^{2} \mathrm{~s}^{-3}$ \\
\hline \multicolumn{4}{|l|}{ Monin-Obhukov similarity } \\
\hline Friction velocity that includes gustiness & coare35vnWarm & usr & $\mathrm{ms}^{-1}$ \\
\hline Wind stress & coare $35 \mathrm{vnWarm}$ & tau & $\mathrm{Nm}^{-2}$ \\
\hline Temperature scaling parameter & coare35vnWarm & tsr & $\mathrm{K}$ \\
\hline Specific humidity scaling parameter & coare $35 \mathrm{vnWarm}$ & qsr & $\mathrm{g} \mathrm{kg}^{-2}$ \\
\hline Thermal roughness length & coare35vnWarm & $\mathrm{zOt}$ & $\mathrm{m}$ \\
\hline Moisture roughness length & coare35vnWarm & $\mathrm{zOq}$ & $\mathrm{m}$ \\
\hline Wind stress transfer (drag) coefficient at $z_{u}$ & coare35vnWarm & $\mathrm{Cd}$ & \\
\hline Sensible heat transfer coefficient (Stanton number) at $z_{u}$ & coare35vnWarm & $\mathrm{Ch}$ & \\
\hline Latent heat transfer coefficient (Dalton number) at $z_{u}$ & coare35vnWarm & $\mathrm{Ce}$ & \\
\hline Obukhov length scale & coare35vnWarm & $\mathrm{L}$ & $\mathrm{m}$ \\
\hline Monin-Obukhov stability parameter, $z_{u} / L$ & coare35vnWarm & zet & \\
\hline \multicolumn{4}{|l|}{ Surface conditions } \\
\hline Wind speed adjusted to $10 \mathrm{~m}$ & coare35vnWarm & $\mathrm{U} 10$ & $\mathrm{~ms}^{-1}$ \\
\hline Air temp at $10 \mathrm{~m}$ & coare35vnWarm & $\mathrm{T} 10$ & ${ }^{\circ} \mathrm{C}$ \\
\hline Specific humidity at $10 \mathrm{~m}$ & coare35vnWarm & Q10 & $\mathrm{g} \mathrm{kg}^{-1}$ \\
\hline Relative humidity at $10 \mathrm{~m}$ & coare35vnWarm & RH10 & $\%$ \\
\hline Neutral value of wind speed at $z_{u}$ & coare35vnWarm & UN & $\mathrm{ms}^{-1}$ \\
\hline Neutral value of wind speed at $10 \mathrm{~m}$ & coare35vnWarm & UN10 & $\mathrm{ms}^{-1}$ \\
\hline Neutral value of drag coefficient at $10 \mathrm{~m}$ & coare 35 vnWarm & Cdn_10 & \\
\hline Neutral value of Stanton number at $10 \mathrm{~m}$ & coare35vnWarm & Chn_10 & \\
\hline Neutral value of Dalton number at $10 \mathrm{~m}$ & coare35vnWarm & Cen_10 & \\
\hline Sea surface temperature & oare35vnWarm & SST & ${ }^{\circ} \mathrm{C}$ \\
\hline Cool-skin temperature depression & coare35vnWarm & dter & ${ }^{\circ} \mathrm{C}$ \\
\hline Surface saturation specific humidity & coare $35 \mathrm{vnWarm}$ & Qs & $\mathrm{g} \mathrm{kg}^{-1}$ \\
\hline Latent heat of vaporization & coare35vnWarm & $\mathrm{Le}$ & $\mathrm{J} \mathrm{kg}^{-1}$ \\
\hline Evaporation rate & coare35vnWarm & Evap & $\mathrm{mm} \mathrm{h}^{-1}$ \\
\hline
\end{tabular}


Table 6. The vertical grid to which all gas profiles $\left(\mathrm{H}_{2} \mathrm{O}, \mathrm{CO}_{2}\right.$, $\mathrm{O}_{3}, \mathrm{~N}_{2} \mathrm{O}, \mathrm{CO}, \mathrm{CH}_{4}$, and $\mathrm{O}_{2}$ ) were interpolated before being used as input to the Rapid Radiative Transfer Model (RRTMv3.3). Note that the second point $(3.8 \mathrm{~m})$ is at the same height as the surface data.

\begin{tabular}{rrrr}
\hline \multicolumn{4}{c}{ Heights (m) } \\
\hline 0.0 & 1000.0 & 5000.0 & 20000.0 \\
3.8 & 1200.0 & 5500.0 & 25000.0 \\
10.0 & 1400.0 & 6000.0 & 30000.0 \\
25.0 & 1600.0 & 6500.0 & 35000.0 \\
50.0 & 1800.0 & 7000.0 & 40000.0 \\
75.0 & 2000.0 & 7500.0 & 50000.0 \\
100.0 & 2250.0 & 8000.0 & 60000.0 \\
150.0 & 2500.0 & 9000.0 & \\
200.0 & 2750.0 & 10000.0 & \\
250.0 & 3000.0 & 11000.0 & \\
350.0 & 3250.0 & 12000.0 & \\
400.0 & 3500.0 & 13000.0 & \\
450.0 & 3750.0 & 14000.0 & \\
500.0 & 4000.0 & 15000.0 & \\
600.0 & 4250.0 & 16000.0 & \\
700.0 & 4500.0 & 17000.0 & \\
800.0 & 4750.0 & & \\
900.0 & & & \\
\hline
\end{tabular}

by the NOAA/ESRL's Global Monitoring Division (GMD) at American Samoa in March 2015 (Thoning et al., 2015), and distributed using a constant mixing ratio at all heights. Profiles of the other gases were taken from the US Standard Atmosphere tropical profile (McClatchey et al., 1972). All data were interpolated to a pre-determined height grid consisting of 58 levels from 0 to $60 \mathrm{~km}$ (see Table 6). All levels above the termination of the radiosonde were filled using the standard atmosphere. By perturbing profiles with $\pm 0.5^{\circ} \mathrm{C}$ temperature and $\pm 5 \%$ relative humidity, values taken from the manufacturer uncertainty estimates, we estimate a maximum uncertainty of $11.4 \mathrm{~W} \mathrm{~m}^{-2}(<3 \%)$ in the clear-sky calculation.

For each sounding we also calculated LWD using the measured temperature-humidity profile but for a scene containing a hypothetical optically thick cloud positioned at $1 \mathrm{~km}$ to represent an estimate of the maximum LWD for that scene. We used RRTM coupled with the Discrete Ordinate Radiative Transfer (DISORT; Stamnes et al., 1988), and considered only absorption, no scattering. The result is a rough estimate of the maximum LWD for that profile, i.e., the LWD in the presence of a low, optically thick stratiform cloud. We were thus able to calculate a maximum estimate of LWCRE, LWCRE $_{\max }$, using Eq. (1).

Cloud optical depth was not measured during the cruise, but sky cover (in oktas) is available from hourly observations made from the bridge. We converted oktas to fractional sky cover by dividing by 8 , and linearly interpolated these hourly values to the $1 \mathrm{~min}$ resolution of the surface observations.
Then we multiplied the cloud fraction at each sounding time by the corresponding $\mathrm{LWCRE}_{\max }$ to yield an estimate of the actual LWCRE. This LWCRE accounts for cloud fraction, including scattered cloud cover, but assumes all clouds are optically thick; this assumption is reasonable since most of the clouds encountered during the cruise were low- to midlevel cumulus and cumulonimbus. Our final estimate of LWD at each sounding time was computed from Eq. (1) using the estimates of $\mathrm{LWD}_{\text {clr }}$ and LWCRE. This was linearly interpolated to the $1 \mathrm{~min}$ resolution of the surface observations and averaged over each hour, and the resulting time series (Fig. 19) was then used as input to the COARE flux algorithm.

Since $L W D_{\text {clr }}$ is calculated directly from the observations, it is expected to be much more robust than the estimate of LWCRE, which requires more assumptions. In Fig. 19 it is apparent that the LWCRE $E_{\max }$ was somewhat larger at the beginning and end of the cruise, when the total column water vapor was lower (not shown; see also Cox et al., 2015), and fairly consistent during the middle part of the cruise when the ship was between $9^{\circ} \mathrm{N}$ and $8^{\circ} \mathrm{S}$ (the mean $\mathrm{LWCRE}_{\max }$ was $38.1 \mathrm{~W} \mathrm{~m}^{-2}$ during this time). Since it was generally cloudy during the cruise (fractional cloud cover $=69 \%$ ), the mean LWCRE is estimated to be $31.1 \mathrm{~W} \mathrm{~m}^{-2}$ overall, representing just $7.3 \% \pm 3.8 \%(1 \sigma)$ of the LWD. Sensitivity calculations using an assumed cloud base ranging from 0.25 to $5.0 \mathrm{~km}$ in $0.25 \mathrm{~km}$ increments show that the average LWCRE would decrease by about $2.7 \mathrm{~W} \mathrm{~m}^{-2}$ per extra $1 \mathrm{~km}$ of cloud base height (i.e., the mean LWCRE would be $4.3 \%$ smaller (larger) if the assumed cloud base were at $1.5 \mathrm{~km}(0.5 \mathrm{~km})$ ). We performed a second sensitivity study in which we recalculated LWCRE after assigning the cloud bases to reasonable heights based on visual analysis of the radiosonde profiles. Estimating cloud bases in that manner was quite challenging, but while we do not have enough confidence in the estimates to use them in our flux calculation, we think they can put bounds on the possible errors in our $1 \mathrm{~km}$ assumption. Comparing those LWCRE values with the ones based on a nominal $1 \mathrm{~km}$ cloud height revealed maximum differences of $\pm 6 \mathrm{~W} \mathrm{~m}^{-2}$, nearly $20 \%$ of LWCRE on average, which we take to be a reasonable estimate of the error in LWCRE.

\subsection{Bulk flux calculations and final data set}

We used the pressure, air temperature, wind, bulk ocean temperature, solar radiation, and longwave radiation time series described above as input to the COARE flux algorithm (version coare35vnWarm; Edson et al., 2013). In keeping with Fairall et al. (1996), we assumed a surface emissivity of 0.97 and a surface albedo of 0.055 . The resulting time series, together with a subset of the surface time series used as input, constitute the released bulk flux data set (Table 5). Because we had a bulk ocean temperature rather than a true ocean skin temperature, we had the algorithm do a cool-skin calculation. Figure 20a shows the net surface heat flux $Q_{0}$ calculated 


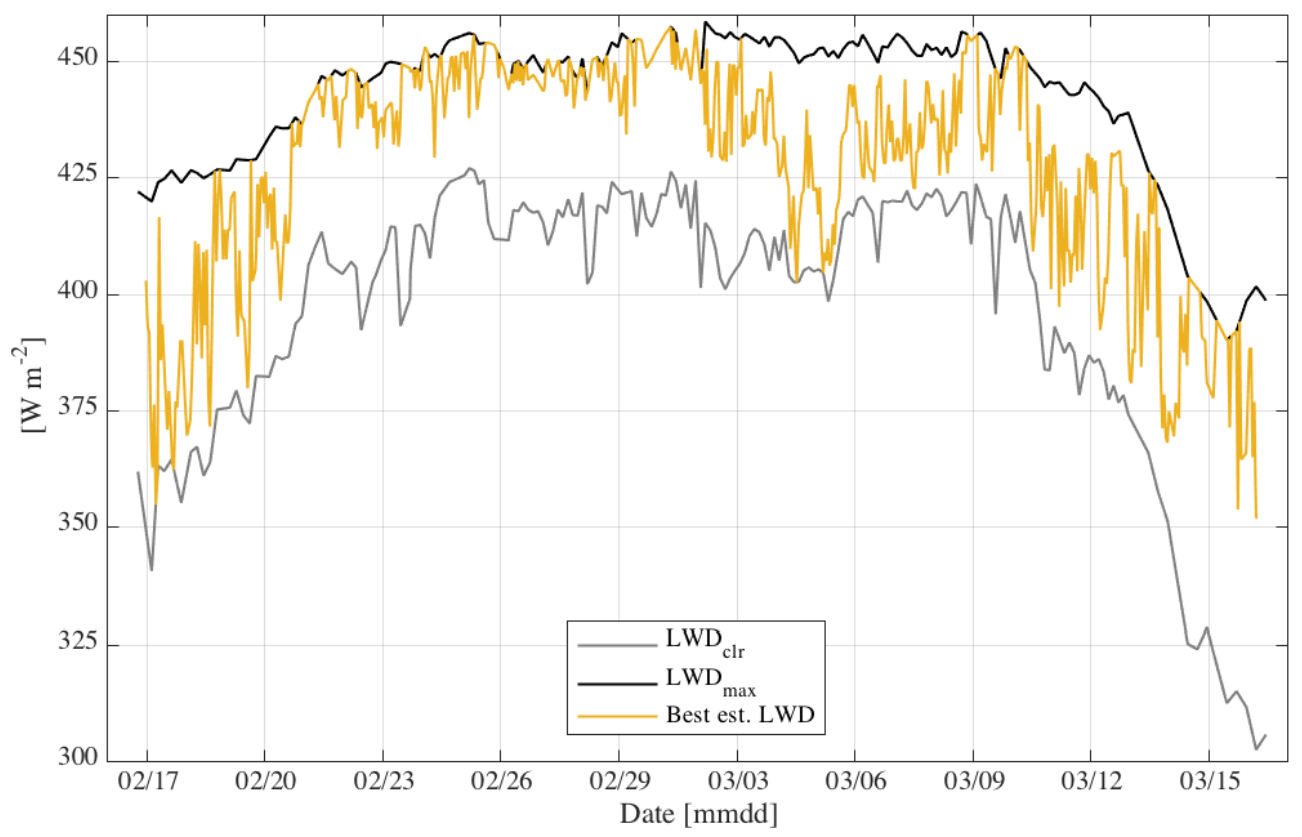

Figure 19. Time series of our best estimate of hourly longwave downwelling radiation (LWD) during the ENRR cruise, compared with hourly estimates during clear-sky conditions, $\mathrm{LWD}_{\mathrm{clr}}$, and in the presence of a hypothetical optically thick cloud scaled by the observed cloud area fraction with a base height of $1 \mathrm{~km}$ a.s.1., $L W D_{\max }$.

Table 7. Estimates of the uncertainties in the longwave radiation variables plotted in Fig. 19 and in other variables used to calculate the surface heat budget in Fig. 20. Refer to the text for details of the estimates. The combined uncertainty is the estimated uncertainty in the surface heat budget, $Q_{0}$, as found by combining the individual estimates in quadrature.

\begin{tabular}{llrl}
\hline Variable & Source of uncertainty & Uncertainty $\left(\mathrm{W} \mathrm{m}^{-2}\right)$ & Notes \\
\hline$Q_{\text {sen }}$ & Various & 3.0 & Fairall et al. (1996) \\
$Q_{\text {lat }}$ & Various & 5.0 & Fairall et al. (1996) \\
SWD, (SWU) & Measured & 4.4 & Relative calibration accuracy of Eppley PSP \\
SWU & Albedo (clouds) & 13.7 & Sensitivity study based on Jin et al. (2011) \\
SWU & Albedo (wind) & 2.3 & Sensitivity study based on Jin et al. (2011) \\
LWU & Emissivity & 4.5 & Based on range reported by Konda et al. (1994) \\
LWU & Surface skin temperature & 1.2 & Fairall et al. (1996) \\
LWD & LW cloud radiative effect & 6.0 & Sensitivity study (see text) \\
LWD & Temperature and humidity profiles & 11.4 & Sensitivity study (see text) \\
\hline Combined uncertainty & 20.8 & \\
\hline
\end{tabular}

from some of the measurements and calculated quantities as

$Q_{0}=Q_{\mathrm{sw}}+Q_{\mathrm{lw}}-Q_{\mathrm{lat}}-Q_{\mathrm{sen}}$,

where $Q_{\text {sw }}$ is the net (absorbed) solar irradiance, $Q_{\text {lw }}$ is the net longwave flux, $Q_{\text {lat }}$ is the bulk latent heat flux out of the ocean, and $Q_{\text {sen }}$ is the bulk sensible heat flux out of the ocean. For reference, both the observed air temperature and ocean temperature are plotted in Fig. 20b. The large amplitude of the diurnal cycle $\left(500-1000 \mathrm{~W} \mathrm{~m}^{-2}\right)$ indicates that uncertainty associated with the estimate of LWD is quite small relative to the magnitude of the other terms, except for the times of the day when the net surface heat budget is switching from net warming to net cooling, and vice versa (near sunrise and sunset).

Since the true values of surface emissivity and surface albedo are not precisely known, nor would they be constant, our assumed values result in uncertainty in the calculations of upwelling longwave and shortwave radiation (LWU and SWU), respectively. The uncertainty in the calculation of LWU associated with the estimation of skin temperature, as well as a range of emissivity values from the literature, are also shown in Table 7. Sensitivity studies using the ocean albedo parameterization of Jin et al. (2011) suggest 0.055 is a poor approximation for clear skies when albedo is dependent on solar zenith angle but is a close approximation for 

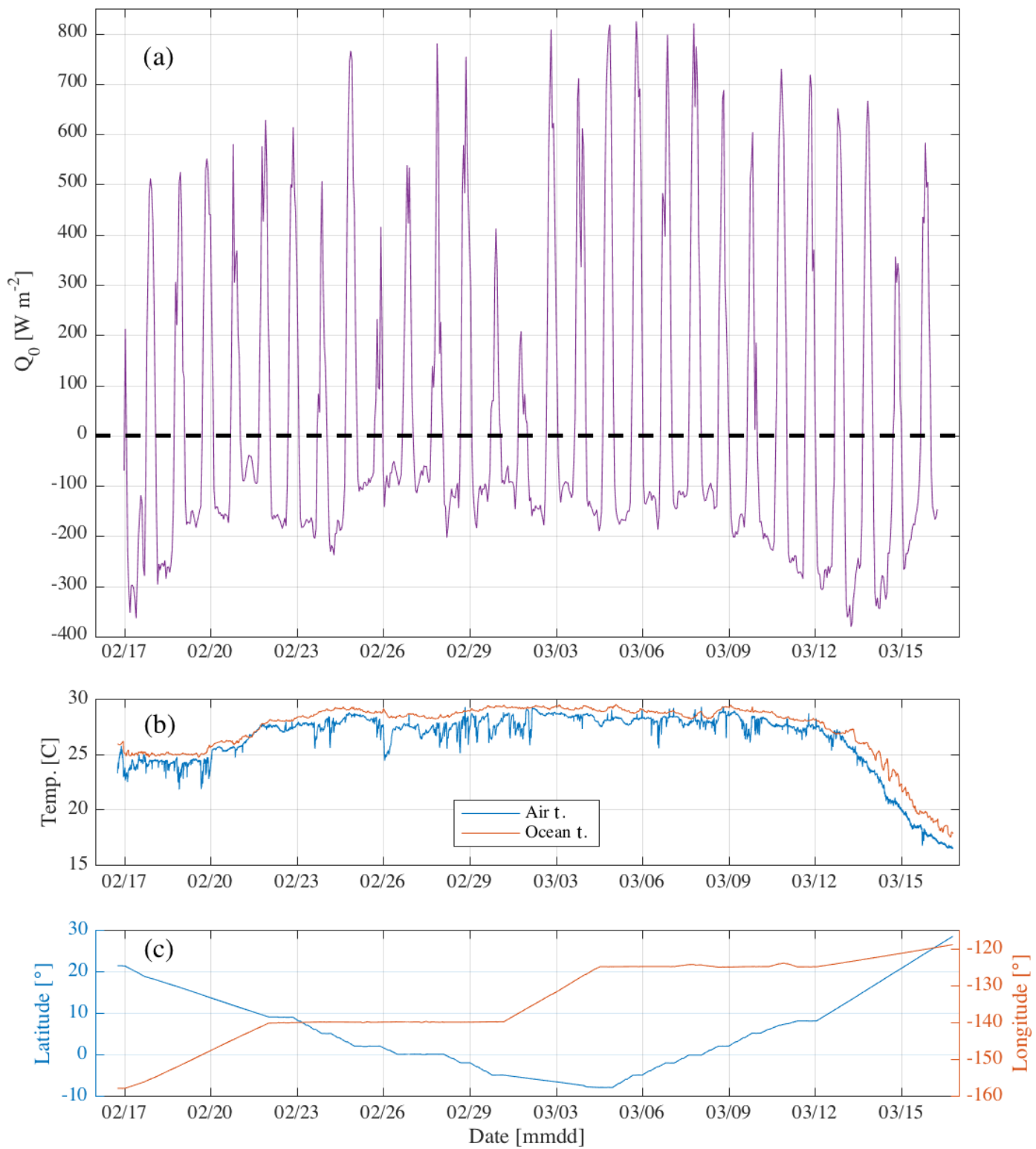

Figure 20. (a) $1 \mathrm{~h}$ average ocean net surface heat flux $\left(Q_{0}\right)$ along NOAA Ship Ronald $H$. Brown's track from 16 February to 17 March 2016. The flux is based on a combination of measurements and calculations with the COARE bulk flux algorithm. (b) For the same time period, $1 \mathrm{~min}$ average ocean temperature at $5 \mathrm{~m}$ depth, and air temperature. (c) Ship position.

the diffuse regime (overcast skies), so our usage is consistent with the high cloud fraction during the cruise. Unfortunately, we do not have a good estimate of the diffuse fraction to use for a calculation of albedo, but by comparing an overcast and clear-sky albedo parameterization using the Jin et al. (2011) routines, we have added the contribution of cloudiness to the uncertainty in SWU (Table 7). Since albedo is also dependent on wind speed (due to its effect on surface roughness), we also estimated an uncertainty in diffuse-regime albedo by comparing estimates including wind speeds with errors of $\pm 1 \mathrm{~m} \mathrm{~s}^{-1}$ to albedo $=0.055$, reporting the largest error (RMSE) of the three-way comparison in calculated SWU
(Table 7). Estimates of uncertainty in the other variables used to calculate $Q_{0}$ are also shown in Table 7. We estimate the combined uncertainty in $Q_{0}$ to be $20.7 \mathrm{~W} \mathrm{~m}^{-2}$.

\section{Data availability and use}

The data sets described here are archived at the NOAA's National Center for Environmental Information (NCEI), with DOIs as follows: surface meteorology from Kiritimati (https://doi.org/10.7289/V51Z42H4), surface meteorology and SST from NOAA Ship Ronald H. Brown (https://doi.org/10.7289/V5SF2T80), 
and surface fluxes from NOAA Ship Ronald $H$. Brown (https://doi.org/10.7289/V58050VP). They are also available, together with sample code to read the data, from NOAA/ESRL/PSD at https: //www.esrl.noaa.gov/psd/enso/rapid_response/data_pub/. Users of these data must cite the appropriate DOI and reference the data as indicated below.

Cox, C., and Hartten, L.: El Niño Rapid Response (ENRR) field campaign: Surface Fluxes from NOAA Ship Ronald H. Brown, 2016-02 to 2016-03 (NCEI Accession 0167875), Version 1.1, NOAA/National Centers for Environmental Information, https://doi.org/10.7289/V58050VP, 2017.

Cox, C., Wolfe, D., Hartten, L., and Johnston, P.: El Niño Rapid Response (ENRR) Field Campaign: Surface Meteorological and Ship Data from the NOAA Ship Ronald H. Brown, February-March 2016 (NCEI Accession 0167875), Version 1.1, NOAA/National Centers for Environmental Information, https://doi.org/10.7289/V5SF2T80, 2017.

Hartten, L., Johnston, P., Cox, C., and Wolfe, D.: El Niño Rapid Response (ENRR) Field Campaign: Surface Meteorological Data from Kiritimati Island, JanuaryMarch 2016 (NCEI Accession 0161526), Version 1.1, NOAA/National Centers for Environmental Information, https://doi.org/10.7289/V51Z42H4, 2017.

The data from Kiritimati start on 25 January 2016, 03:07:43 UTC and end on 28 March 2016, 19:14:43 UTC, with four gaps in one or more parameters lasting $1 \mathrm{~h}$ or more (Table 3). The ship data start on 16 February 2016, 18:32 UTC and end on 16 March 2016 from 18:50 to 18:57 UTC, depending on the parameter.

Each data set is in the form of a single file written in the NASA Ames Format for Data Exchange (hereafter "NASAAmes Format"); see Gaines and Hipskind (1998) as well as the Centre for Environmental Data Analysis (CEDA) explanatory material (Centre for Environmental Data Analysis, 2002). NASA-Ames Format's plain-text (ascii) nature makes it portable to any machine and easily accessible to users with limited computer resources; the rich metadata in the mandatory and optional header sections make it selfdescribing. NASA-Ames Format requires that the total number of header lines be the first number in the first line of the file, and that the data following the header lines be space-delimited. Our files use the last header line to provide rudimentary column headers for the data that follow, which makes importing the data into spreadsheets and starting to work with them fairly straightforward. Time is the independent variable in all the files, and is presented as days since 1900-01-01 00:00:00+00:00, i.e., since 1 January 1900, 00:00:00 UTC. Users working with the data from Kiritimati Island, especially those interacting with residents and local records, should keep in mind that Kiritimati is in the Line Islands Time (LINT) time zone, UTC +14 . Users who prefer to work with data in netCDF format may build their own routines to do so, or may use software such as NASA Ames Processing in PYthon (NAPPy, available at https://github.com/cedadev/nappy). We would caution users to carefully cross-check the output of any conversion software, to make sure that it correctly puts into the netCDF file(s) all the original data as well as the metadata contained in the "special comment" and "normal comment" header sections.

\section{Conclusions}

As the 2015/2016 El Niño gathered strength, the NOAA's ESRL/Physical Sciences Division conceived the idea of a rapidly deployed multi-platform field campaign to meet a variety of operational and research goals (Dole et al., 2018). Observations during the ENRR field campaign, which involved many partners in and outside of the NOAA, included almost 10 weeks of surface meteorology from Kiritimati Island and 4 weeks of surface meteorology from NOAA Ship Ronald H. Brown in the central equatorial Pacific. These data, which were collected at both sites primarily to support radiosonde measurements, have issues caused primarily by instrument failure, out-of-calibration instruments, and less than optimal instrument placement. Some of the issues are a sideeffect of the rapid nature of the campaign planning and deployment; others are endemic on crowded research vessels or in remote and geographically challenging locations.

We have carefully vetted the data against expectations and alternate observations when available, identifying issues and minimizing their impacts by making corrections when possible. We have also estimated air-sea surface fluxes from the ship's data. The final data products that are described in this paper have been placed in a long-term repository and are freely accessible for users. Each file contains considerable internal documentation; this article serves as a detailed description of the instrumentation, siting, issues, and corrections. Highlights of the data sets include the high-resolution measurements of nearly a meter of rainfall at Kiritimati and continuous measurements of ocean and air temperatures in the heart of the El Niño warming as the ship visited the TAO buoys along 140 and $125^{\circ} \mathrm{W}$. These data represent a rich resource for local studies, for inclusion in models of lo$\mathrm{cal} /$ regional processes, or for comparison with satellite observations or model simulations. 


\section{Appendix A: Calculation details for circular statistics}

The circular statistics presented in Table 4 and discussed in Sect. 3.1.3 are predominantly based on Fisher (1995) and MATLAB code described in Berens (2009), itself strongly reliant on Fisher's book. Since most of the statistics are not yet often used in meteorological work, and since some alterations have been made to Berens' code, the calculations are described here. Discussion of the rationale and details behind the equations is to be found in the cited references.

The sample mean direction $\bar{\theta}$ and mean resultant length $\bar{R}$ are obtained by vector averaging the $n$ winds in the sample (Fisher, 1995, Eq. 2.7-2.9). The sample median $\widetilde{\theta}$ is found by determining "the diameter that divides the data into two equal sized groups", and is either the wind direction nearest "the endpoint of the diameter closer to the center of mass of the data" (for an odd number of wind values) or "half-way between the two closest" wind directions (for an even number of wind values) (Berens, 2009). The sample circular dispersion $\hat{\delta}$, one measure of the spread of the data, is calculated as per an online Erratum (Fisher, 2017) using

$\hat{\delta}=\left(1-\hat{\alpha}_{2}\right) /\left(2 \bar{R}^{2}\right)$

where

$\hat{\alpha}_{2}=(1 / n) \sum_{i=1}^{n} \cos 2\left(\theta_{i}-\bar{\theta}\right)$.

This calculation departs from Eq. (2.28) in Fisher (1995),

$\hat{\delta}=\left(1-\hat{\rho}_{2}\right) /\left(2 \bar{R}^{2}\right)$,

where

$\hat{\rho}_{p}=$

$\sqrt{\left[(1 / n) \sum_{i=1}^{n} \cos p\left(\theta_{i}-\bar{\theta}\right)\right]^{2}+\left[(1 / n) \sum_{i=1}^{n} \sin p\left(\theta_{i}-\bar{\theta}\right)\right]^{2}}$

(Fisher, 1995, Eq. 2.25; also Berens, 2009). However, the Erratum's amendment to this form given above makes sense given Fisher's definition of $\hat{\rho}_{2}$ as

$\hat{\rho}_{2}=(1 / n) \sum_{i=1}^{n} \cos 2\left(\theta_{i}-\bar{\theta}\right)$

in his Eq. (2.27).
In a normal distribution, the dispersion about the mean is discussed in terms of the variance; in circular statistics the dispersion of the wind about the mean direction is discussed in terms of the sample concentration parameter $\hat{\kappa}$. This can be simulated with some difficulty (Fisher, 1995, Sect. 3.3.6) or else estimated as a function of the mean resultant length $\bar{R}$ using a table (e.g., Fisher, 1995, Appendix 3) or a conditional formula (Fisher, 1995, Eq. 4.40):

$\hat{\kappa}=\left\{\begin{array}{ll}2 \bar{R}+\bar{R}^{3}+\frac{5 \bar{R}^{5}}{6}, & \bar{R}<0.53 \\ -0.4+1.39 R+\frac{0.43}{(1-\bar{R})}, & 0.53 \leq \bar{R}<0.85 \\ \frac{1}{\left(\bar{R}^{3}-4 \bar{R}^{2}+3 \bar{R}\right)}, & \bar{R} \geq 0.85\end{array}\right.$.

The CircStat MATLAB code (Berens, 2009), which employs the latter, was used to obtain the values in Table 4.

Finally, Fisher (1995, Sect. 5.3.4) outlines a method of testing whether two or more samples have a common mean direction. Since both our samples consist of more than 25 observations and their dispersions are considered comparable because $\frac{\hat{\delta}_{\max }}{\hat{\delta}_{\min }} \leq 4$, we used Fisher (1995, Eq. 5.10-5.13) to calculate the test statistic

$Y_{2}=2\left(N-R_{P}\right) / \hat{\delta}_{0}$

where $N$ is the sum of the two sample sizes,

$R_{P}=\sqrt{\left[\sum_{i=1}^{2} n_{i} \cos \bar{\theta}_{i}\right]^{2}+\left[\sum_{i=1}^{2} n_{i} \sin \bar{\theta}_{i}\right]^{2}}$,

and

$\hat{\delta}_{0}=\sum_{i=1}^{2} n_{i} \hat{\delta}_{i} / N$ 
Author contributions. All the authors spent at least 2 weeks at Kiritimati or 4 weeks aboard NOAA Ship Ronald H. Brown collecting data. SA set up and later relocated the Kiritimati surface instruments, PEJ modified the software for the Kiritimati datalogger to give 1 min data and higher-resolution pressure values, and HAM replaced the power supply after the solar panel failed. PEJ corrected the surface data from Kiritimati with input from LMH; CJC corrected the surface data from NOAA Ship Ronald H. Brown with input from DEW. CJC generated the surface flux data from NOAA Ship Ronald H. Brown. LMH assembled metadata and created the file headers with input from CJC, PEJ, and DEW, and then created the final files from PEJ's and CJC's corrected surface meteorological data and CJC's surface flux data. LMH prepared the manuscript with input from all co-authors.

Competing interests. The authors declare that they have no conflict of interest.

Acknowledgements. The ENRR field campaign was funded by the NOAA through the Office of Oceanic and Atmospheric Research (OAR) as well as the National Weather Service (NWS), the Office of Marine and Aviation Operations (OMAO), and the National Environmental Satellite, Data and Information Service (NESDIS). We thank the Republic of Kiribati for allowing the NOAA to conduct research on Kiritimati Island, and the Kiribati Meteorological Service for their interactions with our observers during and after the field campaign. We appreciate the support we received from the crew of NOAA Ship Ronald H. Brown, in particular NOAA/OMAO Survey Technicians Joshua Gunter and Mark Bradley and NOAA/OMAO Lieutenant Adrienne Hopper. The authors were joined in collecting these data by Xiao-Wei Quan (CIRES and ESRL/PSD) on Kiritimati Island and by Matthew Winterkorn (NVision Solutions and NOAA/National Data Buoy Center) on NOAA Ship Ronald H. Brown. The Kiritimati-based team is grateful to the management and staff of the Captain Cook Hotel, who welcomed ENRR observers and equipment into their lives and went out of their way to make our stay very pleasant, and to John Bryden (JMB Enterprises), whose logistical and supply support was critical to our success. Thanks to Christopher Fairall (ESRL/PSD), Byron Blomquist (CIRES and ESRL/PSD), and Penny Rowe (Northwest Research Associates) for consultations regarding producing surface flux data, Cathy Smith (CIRES and ESRL/PSD) for helping to navigate archival waters and testing conversion software, Don Hooper (CIRES and ESRL/PSD) for scripting magic, Chris Kreutzer (Cherokee Services Group and ESRL/PSD) for testing conversion software, and Christopher Fairall and Robert Zamora (ESRL/PSD) for carefully reading the manuscript. The colors used in many figures are from sets at http://ColorBrewer.org.

Edited by: David Carlson

Reviewed by: two anonymous referees

\section{References}

Berens, P.: CircStat: A MATLAB Toolbox for Circular Statistics, J. Stat. Softw., 31, 1-21, https://doi.org/10.18637/jss.v031.i10, 2009.

Centre for Environmental Data Analysis (CEDA): NASA Ames Format for Data Exchange, available at: https://cedadocs.ceda. ac.uk/73/4/index.html (last access: 18 January 2018), 2002.

Climate Prediction Center (CPC) and International Research Institute for Climate and Society (IRI): $\mathrm{El} \mathrm{Ni} \mathrm{no/Southern}$ Oscillation (ENSO) Diagnostic Discussion, available at: http://www.cpc.ncep.noaa.gov/products/analysis_monitoring/ enso_disc_jun2015/ensodisc.html (last access: 2 March 2017), 2015.

Conley, S. A., Faloona, I., Miller, G. H., Lenschow, D. H., Blomquist, B., and Bandy, A.: Closing the dimethyl sulfide budget in the tropical marine boundary layer during the Pacific Atmospheric Sulfur Experiment, Atmos. Chem. Phys., 9, 87458756, https://doi.org/10.5194/acp-9-8745-2009, 2009.

Cox, C. and Hartten, L.: El Niño Rapid Response (ENRR) Field Campaign: Surface Fluxes from NOAA Ship Ronald H. Brown, 2016-02 to 2016-03 (NCEI Accession 0167875), Version 1.1, NOAA /National Centers for Environmental Information, https://doi.org/10.7289/V58050VP, 2017.

Cox, C. J., Walden, V. P., Rowe, P. M., and Shupe, M. D.: Humidity trends imply increased sensitivity to clouds in a warming Arctic, Nat. Commun., 6, 10117, https://doi.org/10.1038/ncomms10117, 2015.

Cox, C., Wolfe, D., Hartten, L., and Johnston, P.: El Niño Rapid Response (ENRR) Field Campaign: Radiosonde Data (Level 2) from the NOAA Ship Ronald H. Brown, February-March 2016 (NCEI Accession 0161527), Version 1.1, NOAA/National Centers for Environmental Information, https://doi.org/10.7289/V5X63K15, 2017a.

Cox, C., Wolfe, D., Hartten, L., and Johnston, P.: El Niño Rapid Response (ENRR) Field Campaign: Surface Meteorological and Ship Data from the NOAA Ship Ronald H. Brown, February-March 2016 (NCEI Accession 0161528), Version 1.1, NOAA /National Centers for Environmental Information, https://doi.org/10.7289/V5SF2T80, 2017b.

Dee, D. P., Uppala, S. M., Simmons, A. J., Berrisford, P., Poli, P., Kobayashi, S., Andrae, U., Balmaseda, M. A., Balsamo, G., Bauer, P., Bechtold, P., Beljaars, A. C. M., van de Berg, L., Bidlot, J., Bormann, N., Delsol, C., Dragani, R., Fuentes, M., Geer, A. J., Haimberger, L., Healy, S. B., Hersbach, H., Hólm, E. V., Isaksen, L., Kållberg, P., Köhler, M., Matricardi, M., McNally, A. P., Monge-Sanz, B. M., Morcrette, J.-J., Park, B.-K., Peubey, C., de Rosnay, P., Tavolato, C., Thépaut, J.-N., and Vitart, F.: The ERA-Interim reanalysis: configuration and performance of the data assimilation system, Q. J. Roy. Meteor. Soc., 137, 553-597, https://doi.org/10.1002/qj.828, 2011.

Dole, R. M., Spackman, J. R., Newman, M., Compo, G. P., Smith, C. A., Hartten, L. M., Barsugli, J. J., Webb, R. S., Hoerling, M. P., Cifelli, R., Wolter, K., Barnet, C. D., Gehne, M., Gelaro, R., Kiladis, G. N., Abbott, S., Akish, E., Albers, J., Brown, J. M., Cox, C. J., Darby, L., Boer, G. D., DeLuisi, B., Dias, J., Dunion, J., Eischeid, J., Fairall, C., Gambacorta, A., Gorton, B. K., Hoell, A., Intrieri, J., Jackson, D., Johnston, P. E., Lataitis, R., Mahoney, K. M., McCaffrey, K., McColl, H. A., Mueller, M. J., Murray, D., 
Neiman, P. J., Otto, W., Persson, O., Quan, X.-W., Rangwala, I., Ray, A. J., Reynolds, D. Dellaripa, E. R., Rosenlof, K., Sakaeda, N., Sardeshmukh, P. D., Slivinski, L. C., Smith, L., Solomon, A., Swales, D., Tulich, S., White, A., Wick, G., Winterkorn, M. G., Wolfe, D. E., and Zamora, R.: Advancing Science and Services during the 2015/16 El Niño: The NOAA El Niño Rapid Response Field Campaign, B. Am. Meteorol. Soc., 99, 975-1001, https://doi.org/10.1175/bams-d-16-0219.1, 2018.

Edson, J. B., Zappa, C. J., Ware, J. A., McGillis, W. R., and Hare, J. E.: Scalar flux profile relationships over the open ocean, J. Geophys. Res.-Oceans, 109, C08S09, https://doi.org/10.1029/2003JC001960, 2004.

Edson, J. B., Jampana, V., Weller, R. A., Bigorre, S. P., Plueddemann, A. J., Fairall, C. W., Miller, S. D., Mahrt, L., Vickers, D., and Hersbach, H.: On the Exchange of Momentum over the Open Ocean, J. Phys. Oceanogr., 43, 1589-1610, https://doi.org/10.1175/jpo-d-12-0173.1, 2013.

Evans, M. N., Fairbanks, R. G., and Rubenstone, J. L.: The thermal oceanographic signal of El Niño reconstructed from a Kiritimati Island coral, J. Geophys. Res.-Oceans, 104, 13409-13421, https://doi.org/10.1029/1999JC900001, 1999.

Fairall, C. W., Bradley, E. F., Rogers, D. P., Edson, J. B., and Young, G. S.: Bulk parameterization of air-sea fluxes for Tropical Ocean-Global Atmosphere Coupled-Ocean Atmosphere Response Experiment, J. Geophys. Res.-Oceans, 101, 3747-3764, https://doi.org/10.1029/95JC03205, 1996.

Fairall, C. W., Bradley, E. F., Hare, J. E., Grachev, A. A., and Edson, J. B.: Bulk parameterization of air-sea fluxes: Updates and verification for the COARE algorithm, J. Climate, 16, 571-591, https://doi.org/10.1175/15200442(2003)016<0571:BPOASF>2.0.CO;2, 2003.

Fisher, N. I.: Statistical Analysis of Circular Data, Cambridge University Press, Cambridge, 277 pp., 1995.

Fisher, N. I.: Further erratum for Statistical Analysis of Circular Data, available at: http://www.valuemetrics.com.au/Downloads/ Directional/directional.zip, last access: 28 August 2017.

Gage, K. S., Balsley, B. B., Ecklund, W. L., Carter, D. A., and McAfee, J. R.: Wind profiler-related research in the tropical Pacific, J. Geophys. Res.-Oceans, 96, 3209-3220, https://doi.org/10.1029/90JD01829, 1991.

Gaines, S. E. and Hipskind, R. S.: Format Specification for Data Exchange, Version 1.3, NASA Ames Research Center, 30, available at: http://cloud1.arc.nasa.gov/solve/archiv/archive.tutorial. html (last access: 12 July 2016), 1998.

Hartten, L., Johnston, P., Cox, C., and Wolfe, D.: El Niño Rapid Response (ENRR) Field Campaign: Surface Meteorological Data from Kiritimati Island, January-March 2016 (NCEI Accession 0161526), Version 1.1, NOAA /National Centers for Environmental Information, https://doi.org/10.7289/V51Z42H4, 2017.

Hartten, L. M., Cox, C. J., Johnston, P. E., Wolfe, D. E., Abbott, S., McColl, H. A., Quan, X.-W., and Winterkorn, M. G.: Ship- and island-based soundings from the 2016 El Niño Rapid Response (ENRR) field campaign, Earth Syst. Sci. Data, 10, 1165-1183, https://doi.org/10.5194/essd-10-1165-2018, 2018.

Hosom, D. S., Weller, R. A., Payne, R. E., and Prada, K. E.: The IMET (Improved Meteorology) Ship and Buoy Systems, J. Atmos. Ocean. Tech., 12, 527-540, https://doi.org/10.1175/15200426(1995)012<0527:timsab>2.0.co;2, 1995.
Hsu, S. A., Meindl, E. A., and Gilhousen, D. B.: Determining the Power-Law Wind-Profile Exponent under Near-Neutral Stability Conditions at Sea, J. Appl. Meteorol., 33, 757-765, https://doi.org/10.1175/15200450(1994)033<0757:DTPLWP>2.0.CO;2, 1994.

Jin, Z., Qiao, Y., Wang, Y., Fang, Y., and Yi, W.: A new parameterization of spectral and broadband ocean albedo, Opt. Express, 19, 26429-26443, https://doi.org/10.1364/OE.19.026429, 2011.

Joint Subcommittee on Ocean Science and Technology (JSOST): Federal Fleet Status Report: Current Capacity and NearTerm Priorities, Washington, DC, 18 pp., available at: http://www.nopp.org/wp-content/uploads/2016/06/federal_ fleet_status_report_final_03.2016.pdf, 2016.

Konda, M., Imasato, N., Nishi, K., and Toda, T.: Measurement of the sea surface emissivity, J. Oceanogr., 50, 17-30, https://doi.org/10.1007/BF02233853, 1994.

McClatchey, R. A., Fenn, R. W., Selby, J. E. A., Volz, F. E., and Garing, J. S.: Optical Properties of the Atmosphere, 3rd edn., Air Force Cambridge Research Laboratories, Bedford, Mass, Environmental Research Papers, No. 411, 113 pp., available at: www.dtic.mil/dtic/tr/fulltext/u2/753075.pdf, 1972.

McFarlane, S. A., Long, C. N., and Flaherty, J. A.: A climatology of surface cloud radiative effects at the ARM Tropical Western Pacific sites, J. Appl. Meteorol. Clim., 52, 996-1012, https://doi.org/10.1175/JAMC-D-12-0189.1, 2013.

Mlawer, E. J., Taubman, S. J., Brown, P. D., Iacono, M. J., and Clough, S. A.: Radiative transfer for inhomogeneous atmospheres: RRTM, a validated correlated-k model for the longwave, J. Geophys. Res.-Atmos., 102, 16663-16682, https://doi.org/10.1029/97JD00237, 1997.

Moat, B. I., Berry, D. I., and Yelland, M. J.: Airflow distortion at instrument sites on the RV Ronald H. Brown, Southampton Oceanography Centre, University of Southampton, Southampton, Hampshire, UK, 27 pp., 2001.

Morate, O.: 2015 Population and Housing Census Volume 1: Management Report and Basic Tables, National Statistics Office, Ministry of Finance, Bairiki, Tarawa, Republic of Kiribati, 197 pp., available at: http://www.mfed.gov.ki/publications/ census-report-2015-volume-i-final-report (last access: 11 January 2017), 2016.

National Centers for Environmental Information (NCEI): Magnetic Field Calculators, available at: https://www.ngdc.noaa.gov/ geomag-web/\#declination, last access: 18 March 2016.

National Data Buoy Center (NDBC): TAO Mooring Information, available at: http://tao.ndbc.noaa.gov/proj_overview/mooring ndbc.shtml (last access: 27 March 2017), 2010a.

National Data Buoy Center (NDBC): TAO Sensor Specifications, available at: http://tao.ndbc.noaa.gov/proj_overview/ sensors_ndbc.shtml (last access: 27 March 2017), 2010b.

Ralph, F. M., Prather, K. A., Cayan, D., Spackman, J. R., DeMott, P., Dettinger, M., Fairall, C., Leung, R., Rosenfeld, D., Rutledge, S., Waliser, D., White, A. B., Cordeira, J., Martin, A., Helly, J., and Intrieri, J.: CalWater field studies designed to quantify the roles of atmospheric rivers and aerosols in modulating U.S. west coast precipitation in a changing climate, B. Am. Meteorol. Soc., 97, 1209-1228, https://doi.org/10.1175/bams-d-1400043.1, 2016

Scott, D. A. (Ed.): A Directory of Wetlands in Oceania, Slimbridge, UK and Kuala Lumpur, Malaysia, 370 pp., 1993. 
Stamnes, K., Tsay, S. C., Wiscombe, W., and Jayaweera, K.: Numerically stable algorithm for discrete-ordinate-method radiative transfer in multiple scattering and emitting layered media, Appl. Optics, 27, 2502-2509, https://doi.org/10.1364/AO.27.002502, 1988.

Thoning, K. W., Kitzis, D. R., and Crotwell, A.: Atmospheric Carbon Dioxide Dry Air Mole Fractions from quasi-continuous measurements at American Samoa, Version 2016-8, updated annually, NOAA Earth System Research Laboratory (ESRL) Global Monitoring Division (GMD), https://doi.org/10.7289/V51834DB, 2015.

Vaisala Oyj: User's Guide: Ground Check Set GC25, Vaisala Oyj, M210329EN-E, Helsinki, Finland, 43 pp., available at: www. vaisala.com (last access: 20 July 2017), 2006.

Vaisala Oyj: DigiCORA ${ }^{\circledR}$ User's Guide, M210488EN-F, Vaisala Oyj, Helsinki, Finland, 113 pp., available at: www.vaisala.com (last access: 20 July 2017), 2010.

Vaisala Oyj: Vaisala Radiosonde RS92-SGP User's Guide, Vaisala Oyj, M210295EN-J, Helsinki, Finland, 54 pp., available at: www.vaisala.com (last access: 28 January 2016), 2015.
Wang, J., Cole, H. L., Carlson, D. J., Miller, E. R., Beierle, K., Paukkunen, A., and Laine, T. K.: Corrections of Humidity Measurement Errors from the Vaisala RS80 Radiosonde - Application to TOGA COARE Data, J. Atmos. Ocean. Tech., 19, 981-1002, https://doi.org/10.1175/15200426(2002)019<0981:Cohmef>2.0.Co;2, 2002.

Woods Hole Oceanographic Institution (WHOI): ASIMET Module Specifications, available at: http://frodo.whoi.edu/asimet/ asimet_module_specs.html\#bpr_mod (last access: 31 March 2017), 2010a.

Woods Hole Oceanographic Institution (WHOI): ASIMET Sensors, available at: http://www.whoi.edu/instruments/viewInstrument. do?id=14686 (last access: 31 March 2017), 2010 b.

World Meteorological Organization: Manual on the Global Observing System, 2010 edn., WMO (Series) no. 544, Secretariat of the World Meteorological Organization, Geneva, Switzerland, 2013.

Zipser, E. J.: The Line Islands Experiment, its place in tropical meteorology and the rise of the fourth school of thought, B. Am. Meteorol. Soc., 51, 1136-1146, 1970. 